\title{
Towards a consistent mechanism of emulsion polymerization-new experimental details
}

\author{
Klaus Tauer • Hugo Hernandez • Steffen Kozempel • \\ Olga Lazareva $\cdot$ Pantea Nazaran
}

Received: 11 September 2007 /Revised: 25 October 2007 / Accepted: 26 October 2007 / Published online: 3 December 2007

(C) Springer-Verlag 2007

\begin{abstract}
The application of atypical experimental methods such as conductivity measurements, optical microscopy, and nonstirred polymerizations to investigations of the 'classical' batch ab initio emulsion polymerization of styrene revealed astonishing facts. The most important result is the discovery of spontaneous emulsification leading to monomer droplets even in the quiescent styrene in water system. These monomer droplets with a size between a few and some hundreds of nanometers, which are formed by spontaneous emulsification as soon as styrene and water are brought into contact, have a strong influence on the particle nucleation, the particle morphology, and the swelling of the particles. Experimental results confirm that micelles of low-molecular-weight surfactants are not a major locus of particle nucleation. Brownian dynamics simulations show that the capture of matter by the particles strongly depends on the polymer volume fraction and the size of the captured species (primary free radicals, oligomers, single monomer molecules, or clusters).
\end{abstract}

Keywords Mechanism of emulsion polymerization . Particle nucleation $\cdot$ Radical capture $\cdot$ Swelling

K. Tauer $(\bowtie) \cdot$ H. Hernandez $\cdot$ S. Kozempel $\cdot$ O. Lazareva $\cdot$

P. Nazaran

Max Planck Institute of Colloids and Interfaces,

14476 Golm, Germany

e-mail: Klaus.Tauer@mpikg-golm.mpg.de

O. Lazareva

Department of Chemistry and Technology of High Molecular Weight Compounds, Lomonosov Moscow State Academy of Fine Chemical Technology,

Prospect Vernadskogo 86,

119571 Moscow, Russia

\section{Introduction}

Aqueous radical emulsion polymerization is the technically most important synthetic route to polymer dispersions and is used to produce worldwide about 7.5 million metric tons of dry polymer [1]. From a more scientific point of classification, emulsion polymerization belongs to the class of heterophase polymerizations, which comprises furthermore suspension, microsuspension, miniemulsion, microemulsion, dispersion, and precipitation polymerizations. All these techniques, which are leading to various kinds of polymer dispersions, are characterized by their heterogeneous nature. Polymer dispersions are defined as colloidal systems where the polymer is finely distributed in a liquiddispersion medium in the form of stable individual particles. It might be useful to define emulsion polymerization in a general way as polymerization or copolymerization in aqueous systems of any combinations of monomers, which lead to water-insoluble polymers or copolymers in the form of individual polymer particles with a size distribution of diameters in a range typically lower than $1 \mu \mathrm{m}$. The polymer or copolymer particles swell after nucleation with the monomers. These swollen particles represent the reaction loci where most of the monomer is polymerized. In many cases (especially in industrial systems), emulsifiers are present during the polymerization to stabilize the large interfacial area. Despite this characterization is quite rough, it reveals the two most important kinetic features of emulsion polymerization: particle nucleation and particle growth. The first can be considered as phase transition and the latter as sorption process, as matter - at least monomer and radicals - is captured by the particles.

The mechanism of emulsion polymerization has been reviewed several times during the last decade [2-5]. In general, particle nucleation is considered to take place 
either via micellar or homogeneous nucleation in dependence on the hydrophilicity of the monomer and the surfactant concentration. The micellar mechanism considers a smooth transition from a monomer swollen micelle to a polymer particle after entry of a free radical and is applied for hydrophobic monomers such as styrene. For more hydrophilic monomers such as methyl methacrylate, the homogeneous nucleation mechanism assumes that a single growing water-born oligomer radical precipitates when it becomes insoluble in the aqueous phase. This single-chain precipitation is rather unlikely for thermodynamic reasons $[6,7]$ and experimentally not proven. Growth of the particles is mainly determined by both the monomer and the radical concentration per particle. The thermodynamics of swelling of the latex particles with monomer is mainly handled with the Morton-Kaizerman-Altier (MKA) equation [8] despite the fact that it is not absolute and failed quantitatively to predict the monomer concentration per particle [9, 10]. Since the early 1990s, radical entry is modeled, assuming that only radicals with a certain critical chain length are able to enter the latex particles from the aqueous phase $[4,11]$. However, recently this quite restrictive assumption was disproved experimentally [12].

This contribution describes new experimental results aiming to provide a better experimental base for the understanding of emulsion polymerization. Particularly, results will be presented regarding (1) particle nucleation in the absence and presence of both emulsifiers and seed particles, (2) the state of the monomer in water, and (3) the sorption of matter by latex particles.

\section{Experimental information}

Materials and methods The water was taken from a Seral purification system (PURELAB Plus) with a conductivity of $0.06 \mu \mathrm{S} \mathrm{cm}^{-1}$ and degassed prior to use for the polymerization. Styrene (Aldrich) was distilled under reduced pressure to remove inhibitors. Potassium peroxodisulfate (KPS from Sigma Aldrich), sodium dodecyl sulfate (SDS from Roth), cetyl trimethyl ammonium bromide (CTAB from Ferak), and sodium perfluorooctanoate (SPFO from Lancaster) were used as received. Azobisisobutyronitrile (AIBN, Fluka) was recrystallized from methanol before use. Poly(ethylene glycol)-azo-initiator (PEGA200) with an average molecular weight of $568 \mathrm{~g} / \mathrm{mol}$ was synthesized as described elsewhere [13, 14]. 2,2'-Azobis(2-methyl-butyronitrile) (V-59) and 2,2'azobis(2-methyl- $N$-(2-hydroxyethyl)propionamide) (VA-086) were purchased from Wako Pure Chemical Industries and used as received.

The latexes were characterized regarding solids content with a HR73 Halogen Moisture Analyzer (Mettler Toledo) and average particle size (intensity-weighted diameter) with a Nicomp particle sizer (PSS Santa Barbara, USA) at a fixed scattering angle of $90^{\circ}$. Two models were employed differing in the laser power: model 370 with a laser power of $7 \mathrm{~mW}$ and model 380 with a laser power of $35 \mathrm{~mW}$.

The zeta potential $(\xi)$ and the $z$ average particle size $\left(D_{Z}\right)$ were determined according to standard procedures with the Zetasizer 4 (Malvern).

Analytical ultracentrifugation (AUC) was used to determine the particle-size distribution of selected latex samples. The samples were measured with interference optics with water as reference solvent in a Beckman Coulter Optima XLI Analytical Ultracentrifuge (Palo Alto, CA, USA) at 20,000 and $60,000 \mathrm{rpm}$ and $25{ }^{\circ} \mathrm{C}$. The sedimentation coefficient distributions were evaluated by Sedfit 8.9 and then transferred to the algorithm for the determination of particle size [4].

Molecular-weight distributions were determined by gel permeation chromatography (GPC) and used to calculate weight and number average molecular weights $\left(M_{\mathrm{w}}, M_{\mathrm{n}}\right)$. GPC was carried out by injecting $100 \mu$ polymer solutions (solvent tetrahydrofuran) through a Teflon filter with a mesh size of $450 \mathrm{~nm}$ into a thermo separation products setup being equipped with ultra violet (UV; TSP UV1000) and refractive index (RI; Shodex RI-71) detectors in tetrahydrofuran at $30{ }^{\circ} \mathrm{C}$ with a flow rate of $1 \mathrm{ml} / \mathrm{min}$. A column set was employed consisting of three $300 \times 8 \mathrm{~mm}$ columns filled with a MZ-SDplus spherical polystyrene gel (average particle size $5 \mu \mathrm{m}$ ) having a pore size of $10^{3}, 10^{5}$, and $10^{6} \AA$, respectively. This column set allows a resolution down to molecular weights less than $500 \mathrm{~g} \mathrm{~mol}^{-1}$. Number and weight average molecular weights $\left(M_{\mathrm{n}}, M_{\mathrm{w}}\right)$ were calculated based on polystyrene standards (between 500 and $2 \times 10^{6} \mathrm{~g} \mathrm{~mol}^{-1}$ from PSS, Mainz, Germany).

Transmission electron microscopy (TEM) was performed with a Zeiss EM 912 Omega microscope operating at $100 \mathrm{kV}$ and the samples were placed on the grids via suspension preparation.

Optical light microscopy was carried out with a Keyence VH-X digital microscope (Keyence, Osaka, Japan) either with an objective VH-Z100 or VH-Z500 allowing magnifications up to 1,000 and 5,000-fold, respectively.

UV-fluorescence microscopy has been carried out with an Olympus BX51 (Hamburg, Germany) with an excitation wavelength of 330-385 $\mathrm{nm}$. Emission was detected in the wavelength range between 400 and $420 \mathrm{~nm}$.

Polymerizations The kinetic investigations on particle nucleation were carried out in an all-Teflon reactor with a volume of about $500 \mathrm{ml}$ connected to a UV spectrometer (Spekol 11, Carl Zeiss Jena) and equipped with a variety of probes to characterize the changes taking place in the aqueous phase as described in detail elsewhere [5]. During 
these experiments, the stirring was adjusted so slowly that only the aqueous phase was homogenized without dispersing the monomer which is confined on top of the water phase in a glass funnel. A fiber-optical quasi-elastic light-scattering probe (FOQELS) from Brookhaven Instruments, USA, wavelength $785 \mathrm{~nm}$ and scattering angle $135.93^{\circ}$ was used in some experiments as described in [6]. These nucleation experiments were carried out at $70{ }^{\circ} \mathrm{C}$ according to the following procedure. To avoid bubble nucleation during the investigations, the water was carefully degassed by vacuum treatment and boiled. It was filled in the reactor at a temperature above $70{ }^{\circ} \mathrm{C}$. In any case, the temperature, the optical transmission (optical path length $9.8 \mathrm{~cm}$ ), and the conductivity were recorded.

The polymer from the polymerizations in the presence of surfactant was isolated after freeze-drying the latex and washing the solid repeatedly with water.

Surfactant-free emulsion polymerizations were carried out in an all-glass $500 \mathrm{ml}$ reactor at $70{ }^{\circ} \mathrm{C}$. The experiments have been carried out either under quiescent conditions or with a stirrer speed of $300 \mathrm{rpm}$.

\section{Results and discussions}

\section{Detection of particle nucleation}

Particle nucleation in ab initio batch emulsion polymerizations starts at extremely low solid contents typically much below $1 \%$. Thus, the experimental challenge to detect the onset and follow particle nucleation is quite significant. It turned out that conductivity is an extremely good tool to detect the onset of nucleation in surfactant-free polymerizations [7, 15-18]. This established experimental base is illustrated by the data summarized in Fig. 1. It is necessary to point out that with all probes (conductivity, turbidity, dynamic light scattering, etc.), only properties of the aqueous phase are investigated. The monomer, resting on top of the aqueous phase, is not dispersed by the low stirrer speed that is just enough to homogenize the continuous water phase.

After a certain time, allowing to equilibrate the monomer in water, polymerization was started by injecting the initiator solution (here KPS dissolved in a few milliliters of water) at point 1 . The conductivity rises sharply, and afterwards, it increases due to the decomposition of the peroxodisulfate linearly with time during a definite period of time $\left(t_{\mathrm{N}}\right)$. This behavior can be modeled nicely with peroxodisulfate decomposition kinetics [17]. Suddenly at point 2, within $1 \mathrm{~s}$ to the other, the slope of the conductivity-time curve changes to a smaller value. This bend is the point where massive particle nucleation takes

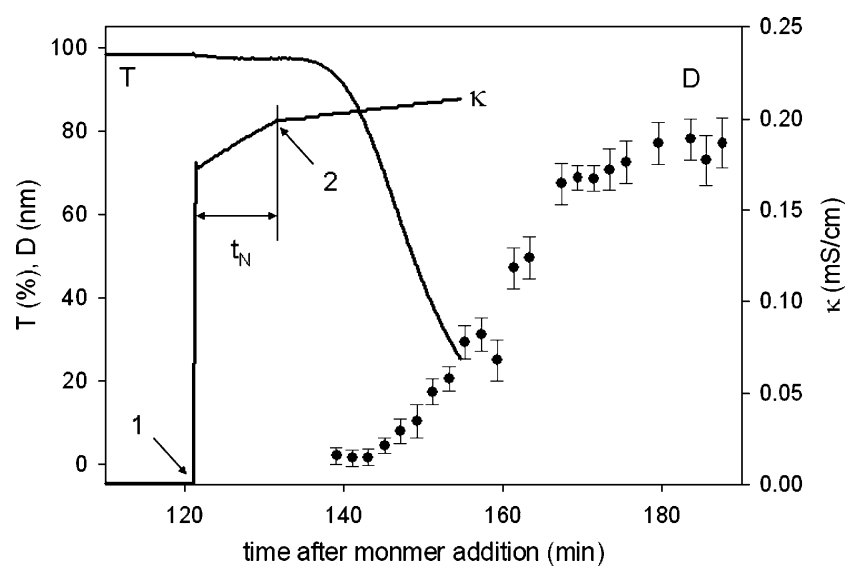

Fig. 1 Typical record of the initial period of surfactant-free emulsion polymerization with on-line determination of transmission $(T)$, conductivity $(\kappa)$, and average particles size ( $D$, FOQELS); experimental conditions: $70{ }^{\circ} \mathrm{C}, 400 \mathrm{~g}$ of water, $3.3 \mathrm{~g}$ of styrene, $0.067575 \mathrm{~g}$ of KPS (0.625 mM KPS in the reactor); monomer equilibration time, $120 \mathrm{~min}$; stirring, $70 \mathrm{rpm}$

place, and $t_{\mathrm{N}}$ denotes the nucleation time or the duration of the prenucleation period. The change of the slope takes place as conducting species lose mobility due to incorporation in the electrical double layer of the particles (mainly protons as outlined in [17]). Independent proof that particle nucleation takes place at the bend of the conductivity curve comes from the fact that particles have only been detected with the FOQELS a few minutes after the bend at almost the same time when transmission starts to decrease.

The smallest particles detected with the FOQELS have a diameter below $5 \mathrm{~nm}$ (between 2 and $3 \mathrm{~nm}$ ) and are composed of oligomers with an average molecular weight of about $600 \mathrm{~g} / \mathrm{mol}$. These particles contain between 4 and 15 oligomers, and hence, they prove the aggregative nucleation model which was derived based on the classical nucleation theory $[6,7]$.

In accordance with the aggregative nucleation model, it is experimentally observed that the duration of the prenucleation period decreases with increasing initiator concentration or larger radical flux (cf. Fig. 2a). The experimental $t_{\mathrm{N}}$ data converge to a value of about $6 \mathrm{~min}$ for KPS concentrations greater than $1 \mathrm{mM}$. Higher initiator concentrations (KPS) do not shorten the nucleation period though the overall rate of polymerization after the particle nucleation period can be increased. This behavior during the prenucleation period illustrates the interaction of two effects: (1) the generation of nucleating oligomers (that are nucleable species) by reaction of the free primary radicals, stemming from the water soluble initiator, with the monomer molecules in water and (2) the nucleation step after a critical supersaturation of these oligomers has been reached. The supersaturation - the ratio between concentration and solubility - is influenced by the initiator concentration on two counteracting ways within the frame 
Fig. 2 Dependence of the nucleation time $\left(t_{\mathrm{N}} ; \mathbf{a}\right)$ and of the final average diameter ( $D$ from dynamic light scattering; b) on the potassium peroxodisulfate concentration $\left(C_{\mathrm{KPS}}\right)$ for surfactant-free emulsion polymerization of styrene; other experimental conditions as mentioned in the caption of Fig. 1; data points are average values of four repeats
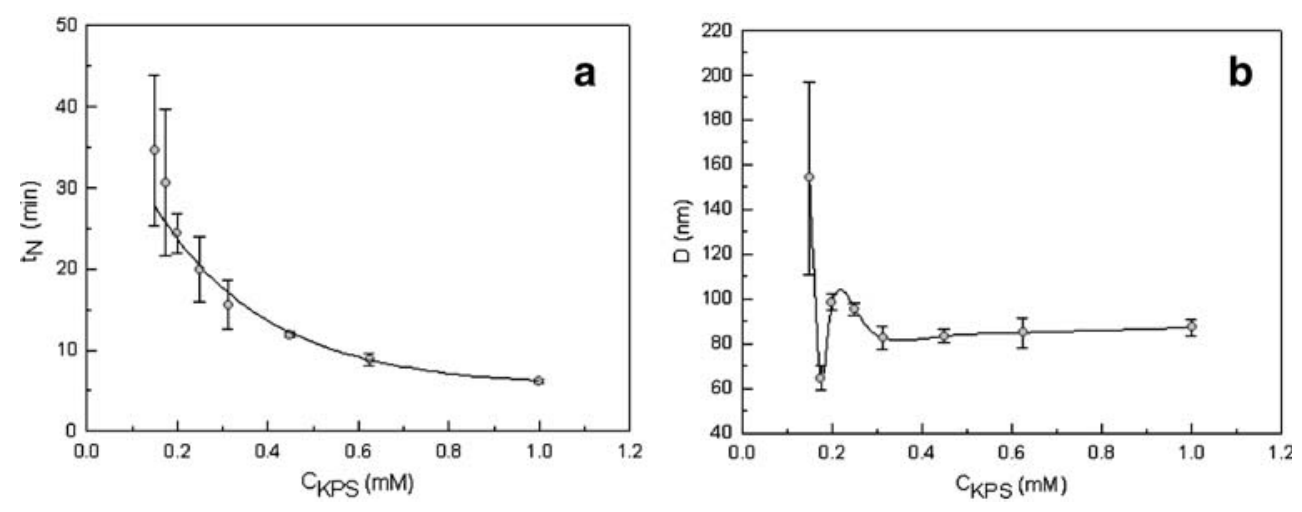

of radical polymerization kinetics. On the one hand, a higher initiator concentration leads to higher supersaturation as the concentration of the nucleating species increases. On the other hand, a higher initiator concentration leads to lower supersaturation as the solubility of the oligomers increases due to their lower molecular weight. At KPS concentrations of 0.1 and $0.05 \mathrm{mM}$, no signs of particle nucleation were observed; that is, neither a bend in the conductivity curve has been observed nor particles have been detected by dynamic light scattering. Obviously, a critical KPS concentration exists, below which the concentration of oligomers is not high enough to reach a critical supersaturation within up to $3 \mathrm{~h}$ after KPS injection.

The lower the KPS concentration, the more scatter the data of the nucleation time depicted in Fig. 2a. This result is also in accordance with the classical nucleation theory as it predicts a strong scatter on even small variation of the experimental conditions due to the exponential dependence of the rate of nucleation on the surface tension, the supersaturation, and the temperature [19]. For high initiator concentrations, the high concentration of nucleable species causes a high supersaturation and reduces the influence of the always-present environmental scatter due to fluctuations.

In contrast to $t_{\mathrm{N}}$, the dependence of the average particle size of the final latexes on the KPS concentration does not display a simple dependence. The standard deviations of the experimental data points suggest that both the maximum and the minimum are real. A quantitative interpretation of this dependence is not possible, but qualitatively it can be considered as the result of two effects running in the opposite direction with increasing amount of KPS. These effects are, on the one hand, increasing stabilization due to a higher concentration of stabilizing end groups and, on the other hand, increasing destabilization due to the increased ionic strength in the continuous phase. Consequently, a dependence with minima and maxima as depicted in Fig. $2 b$ seems reasonable. It is necessary to remark that comparing these data is somehow difficult as both the monomer conversion and the solids content are different. Nevertheless, the highest particle size at the lowest KPS concentration is not to be explained at the moment. The much higher standard deviation might be understandable with the inherent scatter of the nucleation process as discussed already for the duration of the prenucleation period.

Surprisingly, if peroxodisulfate is substituted by nonionic azo-initiators such as AIBN, V-59, VA-086, or PEGA200, a very similar initial behavior of the conductivity is observed as illustrated by the data put together in Fig. 3. These azoinitiators possess a quite different solubility in water, but for all of them, a bend in the conductivity-time curve during surfactant-free emulsion polymerizations of styrene has been observed. Obviously, carbon radicals undergo in water side oxidation reactions leading to ionic species that increase the conductivity in the aqueous phase and stabilize the particles even in the absence of surfactants [20]. This is in accordance with former results where, by means of nuclear magnetic resonance spectroscopy, side oxidation reactions have been detected during the decomposition of azo-initiators in waterbenzene mixtures [21]. Note that V-59 has the lowest water-solubility, and correspondingly, the change in the conductivity takes much longer (hours instead of minutes), but the extent of polymerization inside the monomer layer is extremely high.

In this context, it seems useful to remember the influence of the hydrophobicity of the initiator during the microwaveinduced miniemulsion polymerization of styrene [22]. In this study, it was found that under thermally pulsed conditions, an optimal hydrophobicity of the initiator is required to obtain high conversion and high molecular weight. KPS and V-59 were too hydrophilic and too hydrophobic, respectively, whereas AIBN and PEGA200 turned out to be optimum for achieving high conversion and ultra-high molecular weights simultaneously.

All these results underline the important role of the reactions taking place in the continuous phase during the production of polymer dispersions via heterophase polymerizations. The example of the styrene miniemulsion polymerization shows that a restriction of the reaction to the oil phase by the application of extremely hydrophobic initiators must not be an advantage per se. 


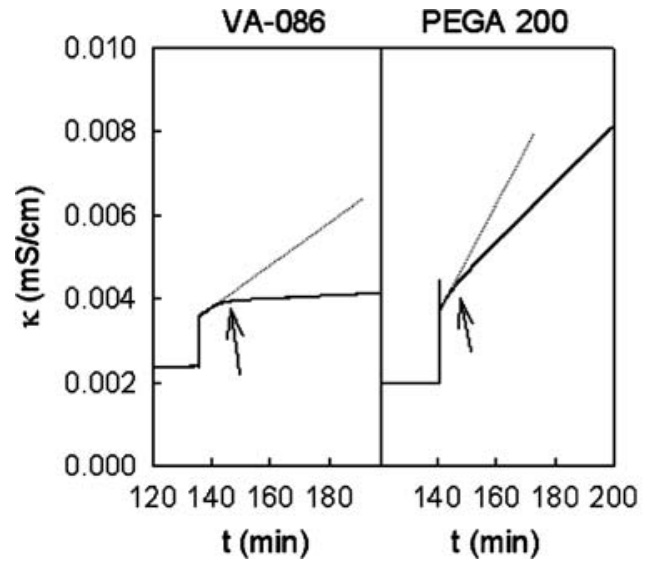

Fig. 3 Conductivity-time curves measured during the initial period of surfactant-free emulsion polymerization of styrene with different azoinitiators; the arrows indicate the bend in the curves; experimental conditions: $70{ }^{\circ} \mathrm{C}, 400 \mathrm{~g}$ of water (for AIBN and V-59) or $410 \mathrm{~g}$ of water (for PEGA200 and VA-086), $3.75 \mathrm{~g}$ of styrene (for AIBN and $\mathrm{V}-59$ ) or $3.3 \mathrm{~g}$ of styrene (for PEGA200 and VA-086), and the following amounts of initiator added $120 \mathrm{~min}$ after placing the

Although both the sharpness and the magnitude of the change in the conductivity-time curve are, for PEGA200 and V-59, not so large as for KPS or AIBN, it is observed in any case. Hence, the data of Fig. 3 prove that also for nonionic initiators, conductivity measurement of the aqueous phase is a valuable tool to detect the onset of particle nucleation in styrene emulsion polymerization. The TEM images of Fig. 4 demonstrate that with AIBN, quite nice monodisperse latexes can be obtained, however, at quite low solids content.

These data directly allow the conclusion that also carbon-centered radicals undergo some side reactions in

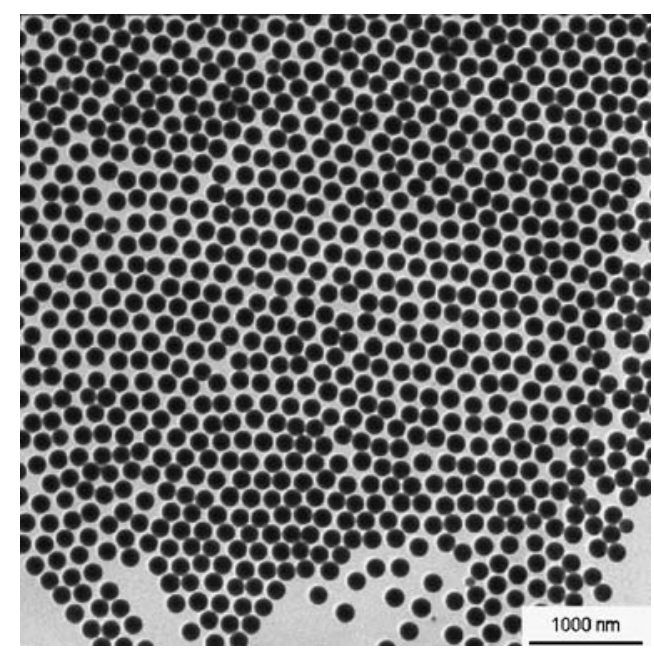

Fig. 4 TEM image of polystyrene latex particles obtained during surfactant-free emulsion polymerization initiated with AIBN after $90 \mathrm{~min}$; solids content of the latex phase below 1\%; average particle size $173 \mathrm{~nm}$; polymerization conditions: all-glass reactor, $70{ }^{\circ} \mathrm{C}, 400 \mathrm{~g}$ water, $20 \mathrm{~g}$ styrene, $0.08 \mathrm{~g}$ AIBN, stirrer speed $50 \mathrm{rpm}$

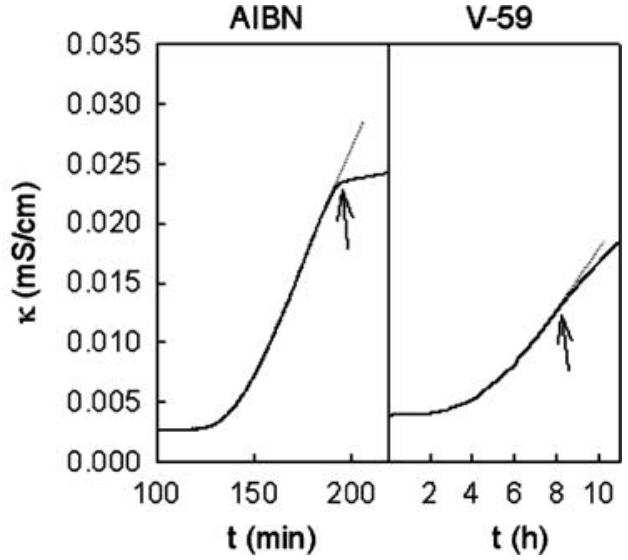

monomer on top of the water phase: $0.072 \mathrm{~g}$ of VA-086, $0.112 \mathrm{~g}$ of PEGA200, $0.075 \mathrm{~g}$ AIBN, and $0.075 \mathrm{~g} \mathrm{~V}-59$ (VA-086 and PEGA200 were added as aqueous solution to water, AIBN and V-59 were added as solution in styrene to the monomer phase); stirring, $70 \mathrm{rpm}$; the dotted lines are just an extension of the initial slope for better visualization

the continuous phase during aqueous emulsion polymerization. Moreover, the side reactions must lead to hydrophilic groups covalently attached to the polymers and thus stabilizing the latex particles. The particles obtained by surfactant-free emulsion polymerization of styrene initiated with AIBN are electrostatically stabilized and possess a pH-dependent zeta potential [20]. Based on these results, one might also expect different decomposition mechanism of hydrophobic initiators inside the particles and in the aqueous phase. Indeed, this was experimentally proven with a ${ }^{13} \mathrm{C}$-NMR study as described in [21].

Micellar nucleation - fact or fancy

Harkins considered in 1947 three loci where the polymerization of the monomer can initiate polymer particles: the soap micelles, the aqueous phase, and the monomer droplets [23]. The latter is only a very minor locus of polymerization but serves as storehouse from which monomer diffuses via the aqueous phase to the micelles or particles where it is polymerized. In dependence on the soap concentration, the micelles or the aqueous phase are dominant during the initial reaction. Furthermore, he argued, based on X-ray scattering data [23-26], that the molecules grow from the soap micelle into the aqueous phase where they continue to propagate and eventually form polymer particles. At this point, micellar soap becomes adsorbed soap and stabilizes the particles.

While referring to Harkins' papers, Smith and Ewart do not consider that radicals can grow out of micelles. They assume that once a radical enters a micelle, it stays inside and polymerizes further, while more monomer diffuses into this polymerizing region. This smooth transition from a 
monomer-swollen micelle to a polymerizing monomerpolymer particle is the core of the micellar particleformation mechanism [27]. With ongoing polymerization, more and more soap adsorbs to the particles until no soap remains in the micellar form, and the soap is no longer effective in particle formation. Smith and Ewart derived the famous relation where the final number of particles $(N)$ scales with the micellar soap $\left(S_{\text {mic }}\right)$ and the initiator concentration $(I)$ as $N \propto S_{\text {mic }}^{3 / 5} \cdot I^{2 / 5}$. However, Roe [28] pointed out that this relation has only little to do with the mechanism of particle formation but rather with the question when does particle formation cease. This relation is not helpful to learn about particle formation as it is in fact independent of the particle nucleation mechanism! Moreover, there are all kinds of data published showing various exponents for experimentally found $N-S^{\alpha}$ relations. Exemplarily, Bartholomé et al. [29] determined $\alpha=0.615$ for emulsion polymerizations of styrene with Amphoseife $\mathrm{C} 18$ as emulsifier and $0.361 \mathrm{~g} / 1 \mathrm{KPS}$ at $45^{\circ} \mathrm{C}$. Contrarily, Hansen and Ugelstad [30] obtained $\alpha=2.67$ also for styrene emulsion polymerization but with SDS as emulsifier and $0.6 \mathrm{~g} / 1 \mathrm{KPS}$ at $60^{\circ} \mathrm{C}$.

If micelles are the loci of particle formation, one might expect that the critical micelle concentration (CMC) is a special point in the dependence of the particle number on the surfactant concentration. To the best of our knowledge, no experimental data are known in the open literature proving such behavior. However, there are data obtained with a particular recipe showing a drastic influence of the CMC of the surfactant on the shape of the $N-S$ curve (cf. Fig. 5). For these investigations, the nonionic PEGA200 initiator was used as this allows the comparison with various types of anionic and cationic surfactants. CTAB and SDS show very smooth and almost identical

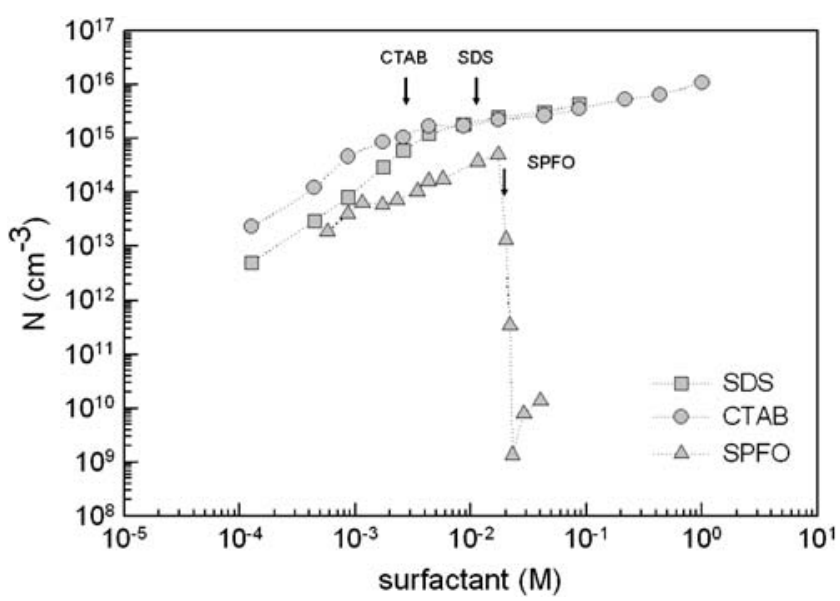

Fig. 5 Log-log plot of the final particle number in dependence on the surfactant concentration; emulsion polymerization of styrene; experimental conditions: $80{ }^{\circ} \mathrm{C} ; 40 \mathrm{~g}$ of water; $10 \mathrm{~g}$ of styrene; $0.673 \mathrm{~g}$ of PEGA200; stirring, 300 rpm; all-glass reactor; the arrows indicate the CMC of the surfactants
$N-S$ dependencies where the $\mathrm{CMC}$ is no particular point. Only for SPFO, the $N-S$ curve shows a break at the CMC, however, in an unexpected way, as the latex became unstable to coagulation. This transition is so sharp that the $N-S$ curve might be considered as kind of 'titration' for the determination of the CMC. Obviously, the perfluoro chains gain more energy by self-aggregation than by adsorption at the poly(ethylene glycol)-coated particle interface. This is an interesting example that micelle formation under particular conditions can prevent the formation of stable particles during emulsion polymerization. Note that the CMCs of the surfactants (SDS, $10.5 \mathrm{mM}$; CTAB, $2.2 \mathrm{mM}$; SPFO, $20 \mathrm{mM}$ ) were determined at polymerization temperature of $80{ }^{\circ} \mathrm{C}$ by both surface tension and conductivity measurements whereby the influence of the styrene monomer was mimicked by toluene.

In the presence of absorbing particles, which can be either micelles or seed particles, the conductivity-time curves should possess a smooth pattern without sharp transitions; at least no bend towards smaller slopes should be observed if no additional particles are formed (no secondary nucleation). In that case, the duration of the prenucleation period is infinite. One might also consider such a case as zero nucleation time as particles are present from the beginning of the reaction. However, this is in contradiction to experimental data (cf. Figs. 2 and 9) showing that there is an infinite nucleation time but no zero nucleation time. Furthermore, a higher molecular weight in the low mass region of the molecular weight distribution can be expected as the swollen micelles are spots with higher monomer concentration in the aqueous phase. Note that the overall polymer formed in ab initio emulsion polymerizations contains chains formed at two different sites. These are initially the aqueous phase (before particle nucleation) and later the monomer-swollen particles. The monomer concentration on both sites differs by orders of magnitude and, hence, also the chain length of the polymer molecules.

The conductivity data put together in Fig. 6a show, for SDS concentrations below and above the CMC, a bend towards a lower slope.

The enormous influence of the SDS concentration on the particle size is illustrated by the particle size distributions shown in the graph of Fig. 7. With increasing surfactant concentration, the particles get smaller and smaller. For SDS concentrations about twice the $\mathrm{CMC}$, the average particle size is below $10 \mathrm{~nm}$, and the turbidity did not decrease during the duration of the experiment. The arrow in graph $\mathrm{c}$ of Fig. 7 indicates the shoulder representing the latex particles. Obviously, the polystyrene particles coexist with a huge number of SDS micelles which are present with the highest concentration in the sample. A decision regarding the particle-nucleation mechanism grounded only 


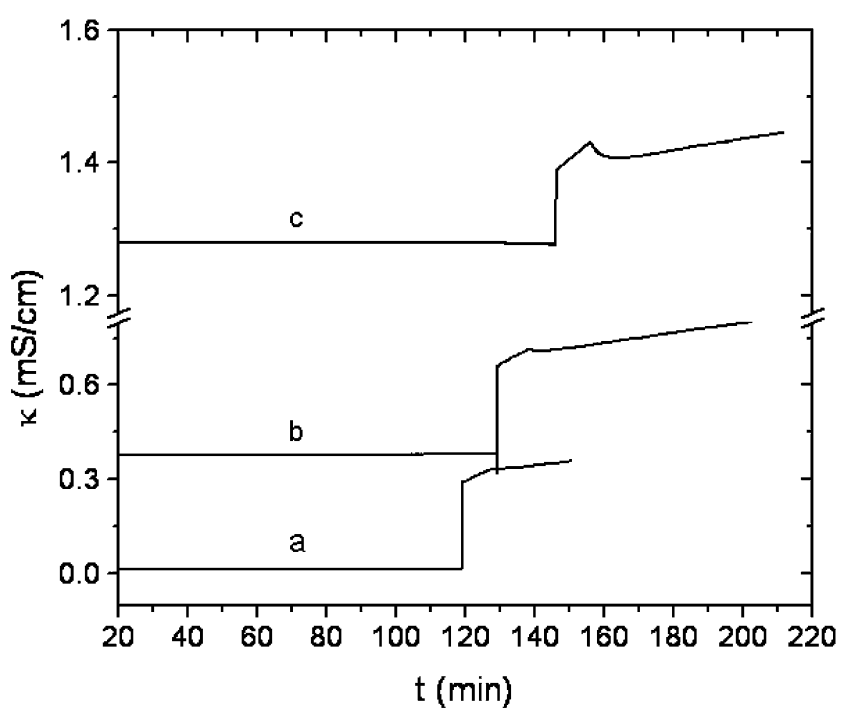

Fig. 6 Conductivity-time curves for emulsion polymerizations of styrene in the presence of various amounts of SDS (curve $a 0.11 \mathrm{mM}$; b $2.9 \mathrm{mM}$; $15 \mathrm{mM}$ ); other experimental conditions: $70{ }^{\circ} \mathrm{C}, 410 \mathrm{~g}$ of water, $0.064 \mathrm{~g}$ of KPS, $3.3 \mathrm{~g}$ of styrene with $t_{\text {equ }}=2 \mathrm{~h}$; stirring, $70 \mathrm{rpm}$; the CMC of SDS under these conditions is about $8 \mathrm{mM}$

on the average particle size of the final latexes is not possible. However, the conductivity data prove that SDS micelles for styrene as monomer do not alter the nucleation behavior. Additionally, the molecular weight data (cf. Table 1) give no hint that micelles are the loci where the initial polymerization reaction takes place. The molecular weight data in the low-molecular-weight region are independent of the SDS concentration. However, the average molecular weights in the high-mass portion of the molecular weight distribution strongly depend on the surfactant concentration. This is an expected behavior, as the particles are smaller the higher the SDS concentration, and smaller particles imbibe less monomer than larger particles $[9,10]$.

If instead of micelles seed particles are used as absorbing species, it is possible to find a critical volume fraction of seed particles where the conductivity curves do not show

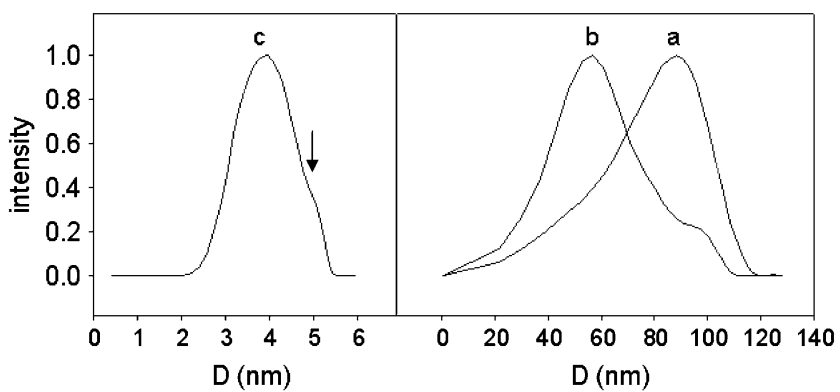

Fig. 7 Particle size distributions of the final latexes for emulsion polymerizations of styrene in the presence of various amounts of SDS (curve $a 0.11 \mathrm{mM} ; b 2.9 \mathrm{mM} ; c 15 \mathrm{mM}$ ) as determined with AUC; other experimental conditions: $70^{\circ} \mathrm{C}, 410 \mathrm{~g}$ of water, $0.064 \mathrm{~g}$ of KPS, $3.3 \mathrm{~g}$ of styrene; stirring, $70 \mathrm{rpm}$; the CMC of SDS under these conditions is about $8 \mathrm{mM}$; the arrow indicates a shoulder in the size distribution of latex $\mathrm{c}$ representing the particles
Table 1 Average molecular weights of the high- and low-molecularmass region of polystyrene particles obtained in the presence of various amounts of SDS (the SDS was removed as described in the "Experimental information")

\begin{tabular}{lll}
\hline $\begin{array}{l}C_{\mathrm{SDS}} \\
(\mathrm{mM})\end{array}$ & $\begin{array}{l}M_{\mathrm{n}} / M_{\mathrm{w}}(\text { low molecular } \\
\text { weight range; g/mol) }\end{array}$ & $\begin{array}{l}M_{\mathrm{n}} / M_{\mathrm{w}} \text { (high molecular } \\
\text { weight range; g/mol) }\end{array}$ \\
\hline 0.11 & $360 / 480$ & $7.7 \times 10^{4} / 1.2 \times 10^{5}$ \\
2.9 & $280 / 600$ & $1.0 \times 10^{4} / 2.4 \times 10^{4}$ \\
13 & $360 / 700$ & None \\
\hline
\end{tabular}

secondary nucleation (cf. Fig. 8b). For these particular seed particles with an average size of $30 \mathrm{~nm}$, the critical volume fraction is between 0.2 and $2 \%$. At the lower seed-volume fraction, the bend in the conductivity curve clearly proves secondary nucleation (cf. Fig. 8a). However, for a seedvolume fraction of $2 \%$, the conductivity curve is a straight line without any sign of bending towards lower slope. This behavior was observed for both possibilities to start the polymerization, that is, either by the addition of styrene monomer or KPS. In the former case, the monomer was added $30 \mathrm{~min}$ after KPS, and in the latter case, the system was equilibrated with monomer for $2 \mathrm{~h}$ before starting the polymerization. If the polymerization is started at low seedvolume fraction with the addition of monomer, the conductivity-time curve exhibits expectedly two bends (Fig. 8a). The first bend occurs immediately after monomer addition and is due to the formation of less mobile species as free radicals react now with styrene molecules. The second bend indicates the nucleation of new particles as in this case the seed particles are unable to capture enough nucleable species to keep their concentration below the critical supersaturation.

Monomer concentration and particle morphology

Besides the flux of primary radicals, either adjusted by the initiator concentration or the temperature [16], the duration of the prenucleation period $\left(t_{\mathrm{N}}\right)$ can also be controlled by the saturation of the aqueous phase with monomer. Varying the equilibration time of the aqueous phase with monomer ( $\left.t_{\text {equ }}\right)$ from zero to about 480 min reduces $t_{\mathrm{N}}$ by almost a factor of 7 (cf. Fig. 9a). For monomer equilibration times longer than about $5 \mathrm{~h}$, the duration of the prenucleation period is practically constant $(6 \pm 0.6 \mathrm{~min})$.

The comparison of the dependence of the duration of the prenucleation period on the monomer equilibration time and the KPS concentration (Fig. 9b) reveals the common nature of both dependencies. They possess similar shape and lead practically to the same minimum value for $t_{\mathrm{N}}$ of $6.1 \pm 0.3$ and $6.0 \pm 0.6 \mathrm{~min}$ for $C_{\mathrm{KPS}}$ and $t_{\mathrm{equ}}$, respectively. The maximum must be different, as for lower KPS concentrations (a concentration somewhere between 0.2 
Fig. 8 Conductivity-time curves for emulsion polymerizations of styrene in the presence of seed particles with a volume fraction of $0.2 \%$ (a) and $2 \%$ (b); the arrows indicate the start of the polymerization by monomer and by KPS addition; experimental conditions: $70{ }^{\circ} \mathrm{C}, 410 \mathrm{~g}$ of water, $0.064 \mathrm{~g}$ of KPS, $3.3 \mathrm{~g}$ of styrene; stirring, $70 \mathrm{rpm}$; the dotted lines are just an extension of the initial slope for better visualization
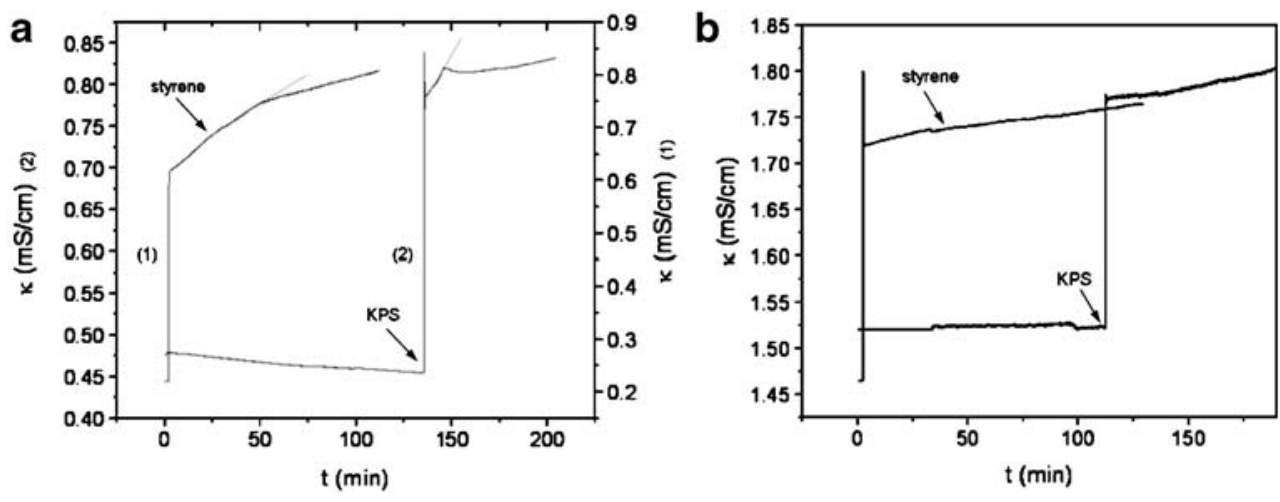

and $0.1 \mathrm{mM})$, particle nucleation has not been detected $\left(t_{\mathrm{N}}\right.$ goes to infinity). If the polymerization is started with the monomer addition $\left(t_{\text {equ }}=0\right)$, it takes 37.5 min until nucleation at the particular KPS concentration.

Furthermore, for polymerizations in the presence of absorbent particles (either micelles or seed particles), the equilibration of the reaction system with monomer is crucial (cf. Fig. 10). The experimental data of the duration of the nucleation period for polymerizations with seed particles or surfactants are considered in dependence on the volume fraction of the foreign material. For SDS concentrations below the $\mathrm{CMC}$, the resulting volume fraction is negative, which has the physical meaning that no micelles but different amounts of nonmicellar SDS are present. Besides the monomer equilibration, the nature of the absorbent particles has a strong influence. Micelles, especially at higher volume fractions, show a completely different dependence than polystyrene seed particles. The summarizing graph of Fig. 10 displays the ways how the presence of absorbent objects influences the particle nucleation during emulsion polymerization. In relation to the absorbent-free situations (characterized by $t_{\mathrm{N}}$-values in regions $\mathrm{A}$ and $\mathrm{B}$ of Fig. 10), the following conclusions can be drawn:

1. For monomer equilibration $\left(t_{\text {equ }}=2 \mathrm{~h}\right)$, the presence of SDS is only of very minor influence on the duration of the prenucleation period as $t_{\mathrm{N}}$ decreases almost linearly from $10.5 \pm 1$ to $8.1 \pm 1$ min for surfactant-free condition and for surfactant concentration five times the CMC, respectively.

2. If, for the situation with monomer equilibration SDS molecules/micelles are replaced by seed particles with the same volume fraction, $t_{\mathrm{N}}$ remains practically unchanged up to a critical volume fraction. At higher volume fraction of seed particles, $t_{\mathrm{N}}$ increases to infinity, and particle nucleation ceases.

3. If the polymerization is started with the addition of monomer $\left(t_{\mathrm{equ}}=0\right)$, the duration of the prenucleation period exhibits, at SDS concentrations below the CMC and at lower volume fractions of seed particles, a qualitatively similar pattern: $t_{\mathrm{N}}$ displays a maximum in dependence on the volume fraction.

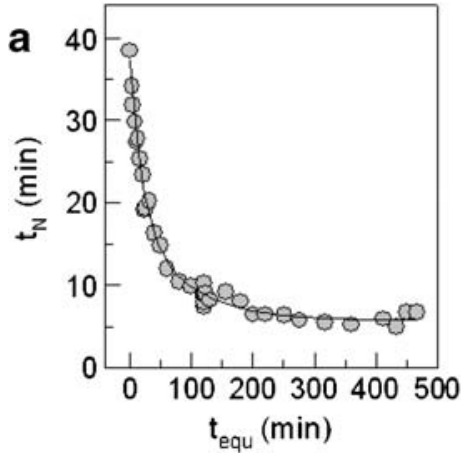

Fig. 9 a Dependence of the duration of the prenucleation period $\left(t_{\mathrm{N}}\right)$ on the equilibration time of the aqueous phase with styrene $\left(t_{\text {equ }}\right)$ and b comparison of $t_{\mathrm{N}}$ in dependence on the reduced monomer equilibration time $\left(t_{\text {equ }, r}=t_{\text {equ }} / t_{\text {equ,max }}\right)$ and on the reduced KPS

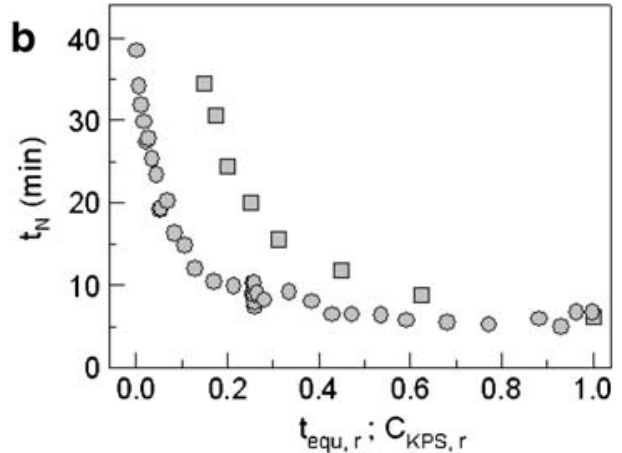

concentration $\left(C_{\mathrm{KPS}, r}=C_{\mathrm{KPS}} / C_{\mathrm{KPS}, \max }\right)$; experimental conditions: $70^{\circ} \mathrm{C}$, $400 \mathrm{~g}$ of water, $0.067575 \mathrm{~g}$ KPS for variable $t_{\text {equ }}, t_{\text {equ }}=120 \mathrm{~min}$ for variable amount of KPS, $3.3 \mathrm{~g}$ of styrene; stirring, $70 \mathrm{rpm}$ 


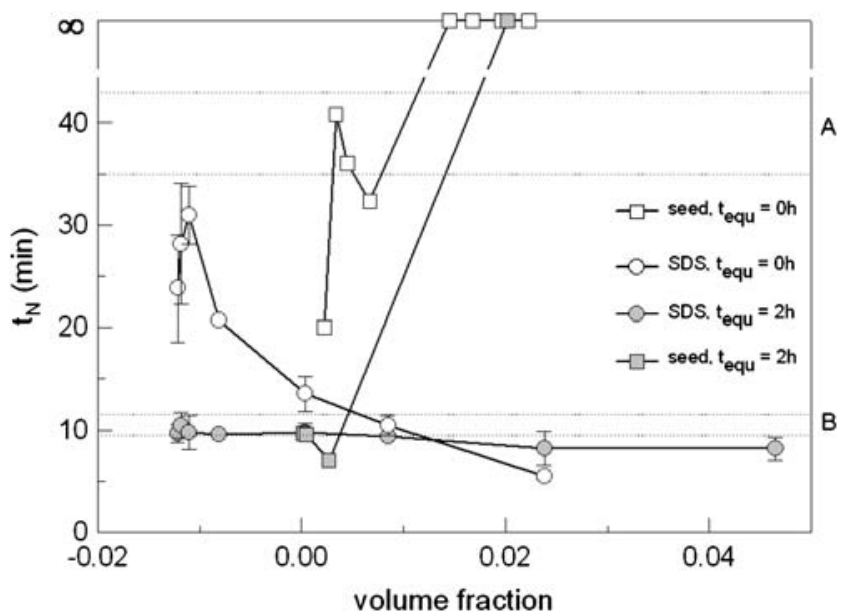

Fig. 10 Nucleation time $\left(t_{\mathrm{N}}\right)$ in dependence on the volume fraction of absorbent particles: SDS molecules (circles) or seed latex particles (squares); the open symbols represent data obtained with empty or unswollen particles (polymerizations started with monomer addition), and the grey symbols data points for swollen absorbent particles after $2 \mathrm{~h}$ equilibration time with monomer (polymerizations started with KPS addition); the dotted lines mark the regions of $t_{\mathrm{N}}=39 \pm 4$ min and $t_{\mathrm{N}}=10.5 \pm 1$ min for absorbent-free polymerizations with zero (a) and $2 \mathrm{~h}$ (b) monomer equilibration time, respectively; other experimental conditions: $70{ }^{\circ} \mathrm{C}, 410 \mathrm{~g}$ of water, $0.064 \mathrm{~g} \mathrm{KPS}, 3.3 \mathrm{~g}$ of styrene; stirring, $70 \mathrm{rpm}$; average data of four repeats for the polymerizations with SDS

4. For surfactant concentrations above the $\mathrm{CMC}$ and at higher volume fractions of seed particles, $t_{\mathrm{N}}$ develops for both systems oppositely as also observed under the conditions of monomer equilibration. The duration of the prenucleation period decreases until it reaches values also observed for monomer-swollen micelles, and it approaches infinity in the presence of seed particles.

The data of Fig. 10 again reveal that the $\mathrm{CMC}$ is obviously no extraordinary point and exhibits no special meaning for particle nucleation. Contrarily, interesting features are observed at SDS concentration far below the CMC but only under monomer-starved conditions $\left(t_{\text {equ }}=0\right)$. The explanation of the maxima in the $t_{\mathrm{N}}$-volume fraction dependences is neither straightforward nor possible within the frame of ordinary emulsion polymerization mechanisms [2-5]. Finding out the common features of surfactant molecules at concentrations below the CMC and seed particles might lead to a rationalization. A long prenucleation period (high $t_{\mathrm{N}}$ ) means that the rate of polymerization is low and vice versa. Obviously, the presence of already low amounts of surfactants or seed particles influences the rate of polymerization in the aqueous phase considerably. One reason might be an enhanced decomposition of the peroxodisulfate by the foreign material, although contradicting results have been published. Brooks et al. [31] observed an acceleration of the KPS decomposition rate in the presence of SDS and/or polymer particles. Okubo and Mori [32] reported that only free SDS molecules (neither adsorbed nor bound in micelles) increased the KPS decomposition rate but that this effect disappeared in the presence of small amount of monomers. An enhanced decomposition rate of KPS can be very likely excluded, as it cannot explain the occurrence of the maximum. Consequently, an influence on the monomer concentration in water remains as possible explanation. As these polymerizations were started with the addition of monomer, any circumstances influencing the transfer of styrene from the reservoir to the water phase can affect the rate of polymerization and change the duration of the prenucleation period. Both the SDS molecules and the seed particles contain hydrophobic portions, and hence, their presence enhances the driving force for the monomer to enter the aqueous phase. This might be the reason for the initial drop of $t_{\mathrm{N}}$. However, the maximum points to the existence of counteracting influences. Seed particles can act as absorbents capturing radicals and monomers, and thus, they can cause also a reduction in the rate of polymerization. Below the $\mathrm{CMC}$, surfactant molecules are usually considered to be molecularly dissolved, and consequently, they are not able to act likewise as absorbents. The situation is complicated, and unraveling requires changed paradigms especially regarding the structure of the monomer-in-water system at surfactant concentrations below the CMC.

All the results presented in Figs. 9 and 10 clearly reveal $t_{\text {equ }}$ as new experimental parameter influencing the particle nucleation kinetics, likewise the initiator concentration. Moreover, the data raise immediately the question regarding the state of the monomer-in-water solution. To get an idea, the transmission measurements have been evaluated carefully already during the monomer equilibration period before starting the polymerization, and two kinds of experiments in other reactors have been carried out. It turned out that during the monomer equilibration period, the transmission in the allTeflon reactor under the conditions of the standard experiment decreases from 100 to about $91 \%$ continuously over about $3 \mathrm{~h}$ before reaching a constant value. With multi-angle laser-light scattering in glass cuvettes, the development of a strong scattering signal in the aqueous phase was observed over a period of some hours after styrene was quiescently placed on top of water [33]. Additionally, the styrene concentration in water was determined by gas chromatography in samples taken from the all-Teflon reactor [15]. The data sets for $r_{\mathrm{G}}$ (radius of gyration from light scattering) and $C_{\text {sty }}$ (styrene concentration in water from gas chromatography) show an interesting correlation when plotted with a common time axis (cf. Fig. 11). The averaged time-dependent data sets show that the average droplet size increases dramatically in the vicinity of the saturation concentration. Over the entire concentration range $\mathrm{d}\left(2 r_{\mathrm{G}}\right) / \mathrm{d} C_{\text {sty }}$ (not shown here) increases 


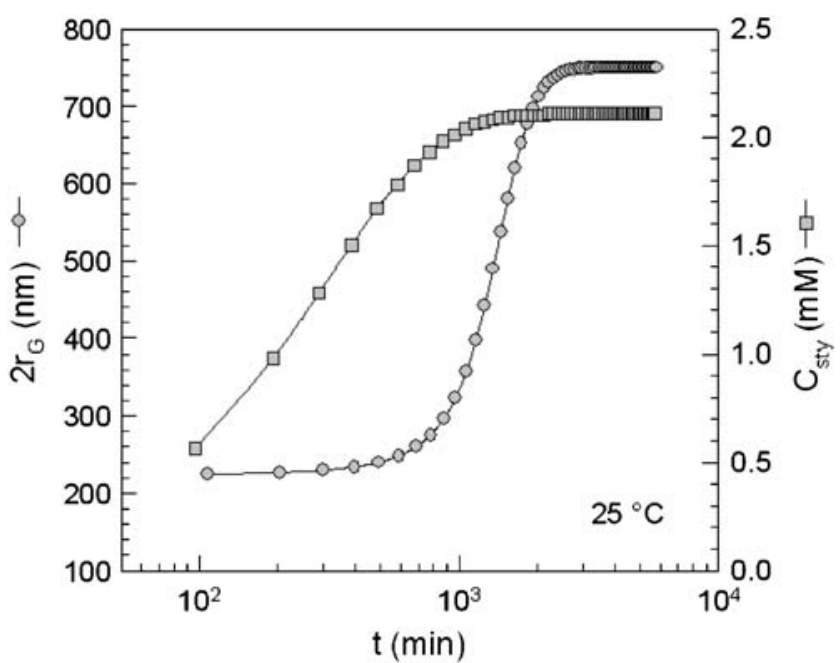

Fig. 11 Change of the radius of gyration of styrene droplets and the concentration of styrene in water at $25^{\circ} \mathrm{C}$; for experimental details, see $[15,33]$

by about a factor of 1,000 . This behavior strongly resembles critical phenomena in the vicinity of phase transition points.

Additional proofs for the existence of styrene droplets in a surfactant-free styrene-in-water solution come from electron microscopy and light microscopy (cf. Fig. 12) $[15,34]$.

The TEM image of the stained styrene-in-water emulsion shows bright and almost spherical spots. These might be the leftovers of the monomer drops which were stabilized by quite thin and still permeable layer of the styrene- $\mathrm{OsO}_{4}$ reaction product. Comparison images of $\mathrm{OsO}_{4}$-in-water solutions show only dark irregularly formed particles. Contrarily, light microscopy shows styrene droplets moving along the interface between water and styrene giving direct visible evidence of spontaneous emulsification at an interface between two immiscible liquids as comprehensively discussed in [34]. Now, it is clear that the decrease of the transmission during the monomer equilibration period is the result of the formation of styrene droplets. The consequences for the following polymerization are enormous. On the one hand, the huge interface of the droplets facilitates monomer diffusion into water. On the other hand, the overall styrene concentration in water is not so that only single molecules dissolved among about $10^{4}$ water molecules. The existence of aggregates reduces the kinetically available concentration. Larger droplets play practically no role for the kinetics as the number of aggregates decreases inversely with the third power of their size. Hence, the concentration of single monomer molecules or dimers and trimers is orders of magnitude larger than that of bigger drops and determines the reaction kinetics with the primary radicals in the aqueous phase.

The discovery that styrene droplets coexist with molecularly dissolved styrene can explain the experimentally observed dependence of the nucleation time on the surfactant concentration (cf. Fig. 10). Like the monomer in the swollen seed particles, the monomer in larger styrene drops is not available for the reaction in the aqueous phase. The presence of surfactant molecules enhances the spontaneous emulsification and influences the droplet size distribution. A higher surfactant concentration increases the number of styrene drops in the aqueous phase but decreases their size. Consequently, the overall interface between styrene and water increases, which, together with the higher Laplace pressure due to the smaller droplet size, causes an increase of the styrene concentration in water that can participate in the polymerization. The reaction rate increases, and the duration of the prenucleation period decreases.

Despite their unimportance as reaction locus for the aqueous phase kinetics, the monomer drops should have a strong impact on the particle morphology. The images of Fig. 13a summarize the influence of the duration of the monomer equilibration on the particle morphology, and Fig. 13b compares the developments of the average molecular weights and of the hydrodynamic average particle size in the course of the polymerization after different monomer equilibration times.

Expectedly, the average molecular weight is higher the longer the duration of the monomer equilibration period. The TEM images reveal very special particle morphologies resembling rather vesicular or hollow particles than solid spheres. The shell of these objects is thicker the higher the average molecular weight. The average molecular weight changes during these polymerizations in a very specific way as it goes through a shallow minimum after about $2 \mathrm{~h}$ independent of the duration of the monomer equilibration period. A reasonable explanation for this minimum might be that the consumption of styrene is faster than its delivery from the monomer phase by diffusion. Under stirred conditions (data not shown in this paper), $M_{\mathrm{n}}$ is after about $50 \mathrm{~min}$ independent of $t_{\mathrm{equ}}$ and increases almost linearly with the polymerization time to values of about $2 \times 10^{4} \mathrm{~g} / \mathrm{mol}$ after $5 \mathrm{~h}$.

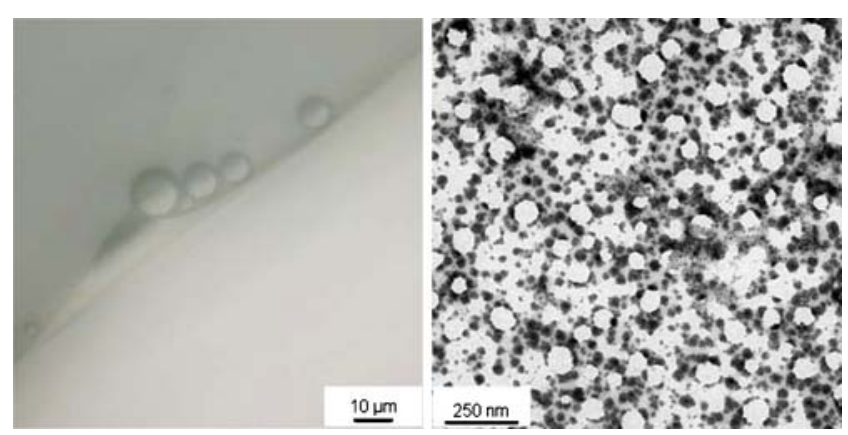

Fig. 12 Light microscopy (left) and electron microscopy (right) images of spontaneously formed styrene drops in pure water; the TEM image was obtained after treating a styrene-in-water solution with $\mathrm{OsO}_{4}$ 
Fig. 13 a TEM images of the particle morphology after polymerization time of $60 \mathrm{~min}$ for surfactant-free emulsion polymerizations of styrene with monomer equilibration times of $0(A), 30(B)$, and $180 \mathrm{~min}(C)$; experimental conditions: allglass reactor, nonstirred, $70{ }^{\circ} \mathrm{C}$, $20 \mathrm{ml}$ of styrene, $562.5 \mathrm{~g}$ of water, $1.25 \mathrm{~g}$ of KPS.

b Development of the number average molecular weight $\left(M_{\mathrm{n}}\right)$ and the average particle size ( $D_{\mathrm{Z}}$, from ZetaSizer) during the surfactant-free emulsion polymerizations of styrene after different monomer equilibration times of 0 (circles), 30

(squares), and $180 \mathrm{~min}$ (triangles); experimental conditions: all-glass reactor, nonstirred, $70{ }^{\circ} \mathrm{C}, 20 \mathrm{ml}$ of styrene, $562.5 \mathrm{~g}$ of water, $1.25 \mathrm{~g}$ of KPS a
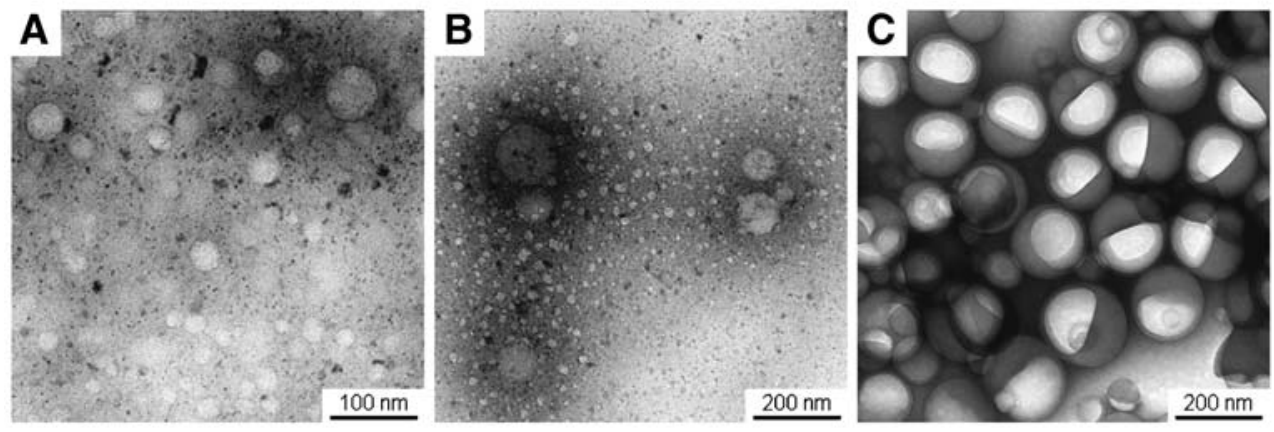

b

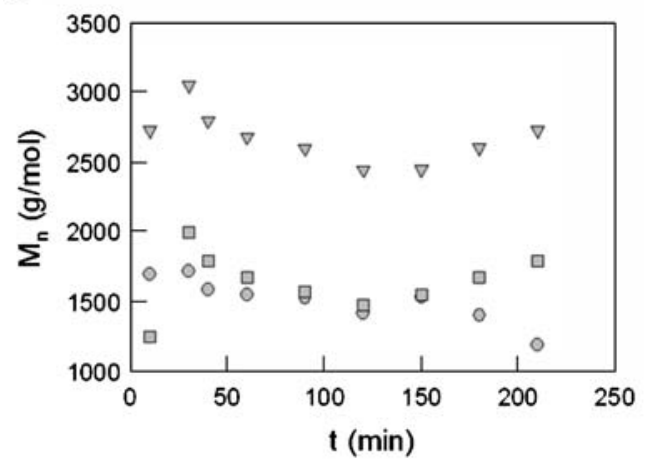

The change of the average hydrodynamic particle size during the polymerization depends, especially within the first hour, strongly on the monomer equilibration time. For short equilibration times, $D_{\mathrm{Z}}$ decreases drastically and remains almost constant thereafter. Basically, the TEM images do not display this behavior. This discrepancy is a strong hint that the scattering structures in the dispersions are no solid structures. During the stirred polymerizations, $D_{\mathrm{Z}}$ increases with the polymerization time and is independent of the prenucleation period.

Besides the duration of the monomer equilibration period, the monomer concentration can also be controlled by the hydrodynamics in the reactor. In the simplest case, this can be done by changing the stirrer speed, as shown by the data of Fig. 14.

The principal particle morphology does not depend on the hydrodynamic conditions. In either case - stirred and nonstirred - the hollow particle morphology is observed. However, the influence of the stirrer speed on the shell thickness of the hollow particles is enormous. The shell grows thicker if the transportation of the monomer to the reaction loci is enhanced due to the stirring.

Both $D_{Z}$ and $\xi$ reveal the strong influence of the hydrodynamics on the properties of the latex particles. Under quiescent conditions, the zeta potential is much lower (much more negative), the shell around the vesicular or hollow particles is much thinner, and $D_{\mathrm{Z}}$ decreases during the polymerization, whereas it increases under
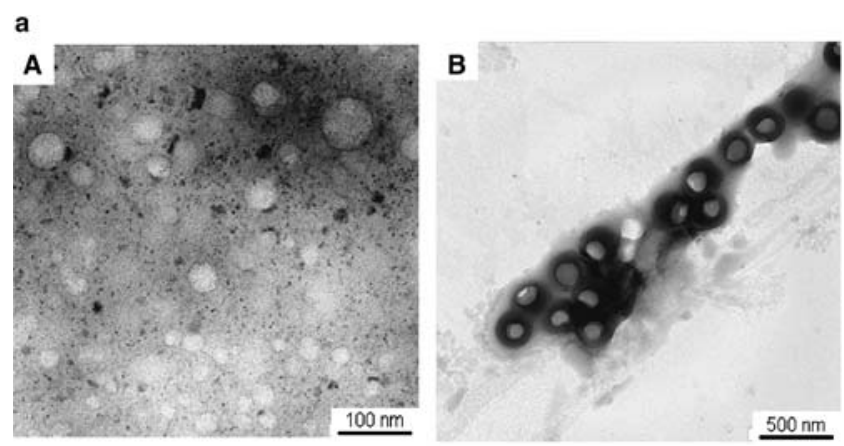

b
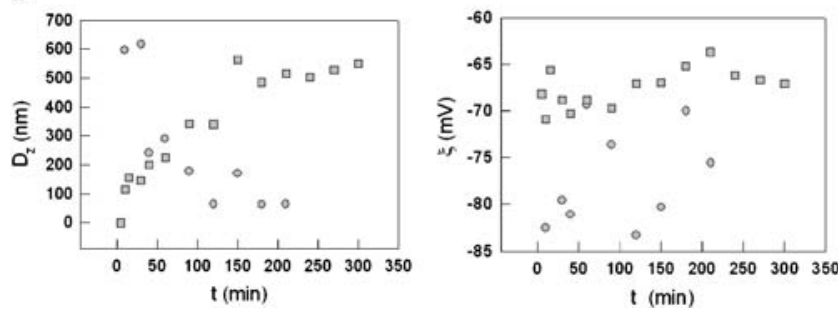

Fig. 14 a TEM images showing particles after polymerization time of $60 \mathrm{~min}$ for surfactant-free emulsion polymerizations of styrene with zero monomer equilibration time, nonstirred $(A)$ and stirred with $300 \mathrm{rpm}(B)$; experimental conditions: all-glass reactor, $70{ }^{\circ} \mathrm{C}, 20 \mathrm{ml}$ of styrene, $562.5 \mathrm{~g}$ of water, $1.25 \mathrm{~g}$ of KPS. b Development of the average particle size $\left(D_{\mathrm{Z}}\right.$, from ZetaSizer) and the zeta potential $(\xi)$ during the surfactant-free emulsion polymerizations of styrene without monomer equilibration under unstirred (circles) and stirred (300 rpm; squares) conditions; further experimental details: all-glass reactor, nonstirred, $70{ }^{\circ} \mathrm{C}, 20 \mathrm{ml}$ of styrene, $562.5 \mathrm{~g}$ of water, $1.25 \mathrm{~g}$ of KPS 
stirred conditions. In addition, stirring leads to higher solids content and to higher molecular weights. The latter is in accordance with the less negative zeta potential of the particles obtained under stirred conditions.

The data depicted in Figs. 10, 11, 12, 13, and 14 disclose the importance of the 'monomer-in-water state' on the outcome during the early stages of emulsion polymerizations. Obviously, the monomer droplets formed after contacting styrene and water are templated or stabilized by small oligomeric particles formed by reaction of the primary sulfate ion radicals with styrene molecules (or dimers or trimers). These oligomeric particles have a size below $5 \mathrm{~nm}$ and are visible as small dark spots on the TEM images (cf. Fig. 15) and consist of a few oligomers with higher electron density due to the higher sulfur and oxygen content than high molecular weight polymer. Note that the chemical structure of these oligomers must necessarily not be regular as expected from radical polymerization kinetics as it is known that both $\mathrm{SO}_{4}^{-}$and also $\mathrm{HO}$ radicals can react with the phenyl ring to give the corresponding (vinyl) cyclohexadienyl radicals [35, 36]. After nucleation, these oligomeric particles adsorb at the interface between the styrene droplets and water as they are neither soluble in water nor in styrene.

This scenario explains all the experimental observations from the spontaneous emulsification to the formation of vesicular or hollow particles. If, however, the polymerization conditions are changed in a way resulting in oligomers with higher molecular weight which are soluble in the droplets, solid particles should be formed. Indeed, this is proven by the data put together in Fig. 16a and b. Here, two polymerizations with different KPS concentrations are compared. The polymerization with the lower initiator concentration leads to polymers with higher average molecular weights and particles with lower average diameters (cf. Fig. 16a). The former follows from the radical polymerization kinetics and the latter from the dependence of droplet and particle stability on the ionic strength. The morphology of the particles is changed in the expected way as the polymerization with the lower initiator concentration leads to solid particles.

Regarding the radical generation in the continuous aqueous phase, the polymerizations with AIBN correspond to polymerizations with low KPS concentrations. Consequently, the particle morphology is always solid as exemplarily shown in Fig. 4.

\section{Absorption of matter by latex particles}

Due to their large surface area, colloidal particles can effectively absorb or imbibe all kinds of materials of either hydrophobic or hydrophilic nature [30]. Radicals and monomers are for emulsion polymerizations of particular importance. Despite the actual situation that the uptake mechanism of both monomers and radicals is considered differently and discussed contradictorily, there are general principles involved which have to be considered.

It has been found that the Morton-Kaizerman-Altier (MKA) Eq. 1 [8] is not suited to describe quantitatively the swelling of latex particles by organic solvents for the polymer $[9,10]$. In MKA Eq. $1, R$ is the gas constant, $T$ the temperature, $v_{1}$ the molecular volume of the swelling agent, $\sigma$ the interfacial tension between the particle and the continuous phase, $\chi$ the Flory-Huggins interaction parameter between polymer and swelling agent, $\phi_{2}$ the volume fraction of polymer in the swollen particles, and $r$ the particle radius. To achieve a better agreement with experimental data, a swelling pressure was introduced that takes into account the work necessary for the disintegration of entangled polymer molecules. Additionally, the agreement with experimental data was improved if the concentration dependence of the Flory-Huggins interaction parameter and the dependence of the interfacial tension on the particle size were considered [9, 10]. The investigation of swelling of large monodisperse latex particles by means of light microscopy revealed some new experimental facts which, on the one hand, can improve

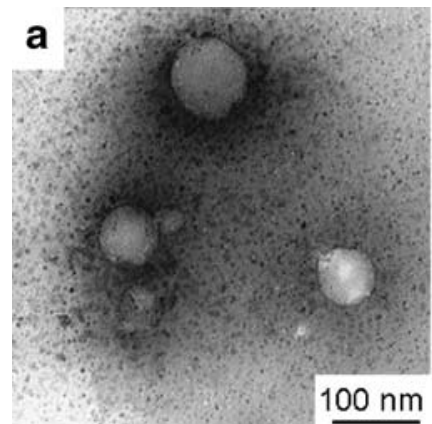

Fig. 15 TEM images illustrating the particle morphology as result of the deposition of oligomeric particles onto styrene droplets during the early stage of unstirred emulsion polymerization; a $t_{\text {equ }}=5 \mathrm{~min}$ after $40 \mathrm{~min}$ polymerization time, $\mathbf{b} t_{\text {equ }}=120 \mathrm{~min}$ after $30 \mathrm{~min}$ polymer-
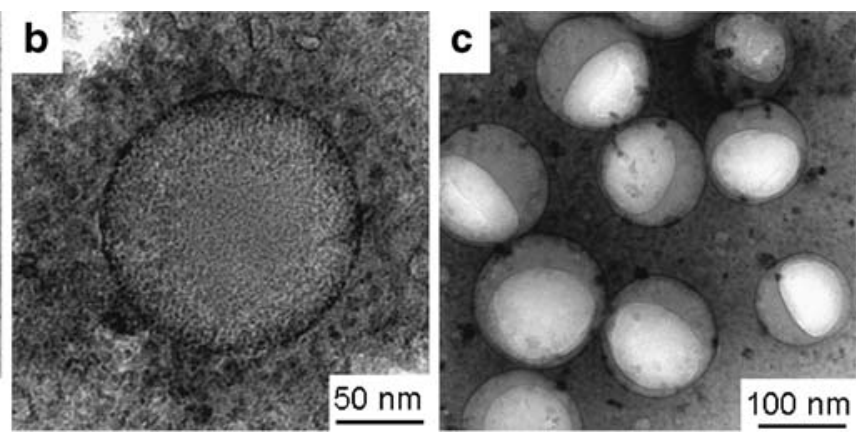

ization time, $\mathbf{c} t_{\text {equ }}=180 \mathrm{~min}$ after $30 \mathrm{~min}$ polymerization time; further experimental details: all-glass reactor, nonstirred, $70{ }^{\circ} \mathrm{C}, 20 \mathrm{ml}$ of styrene, $562.5 \mathrm{~g}$ of water, $1.25 \mathrm{~g}$ of KPS 

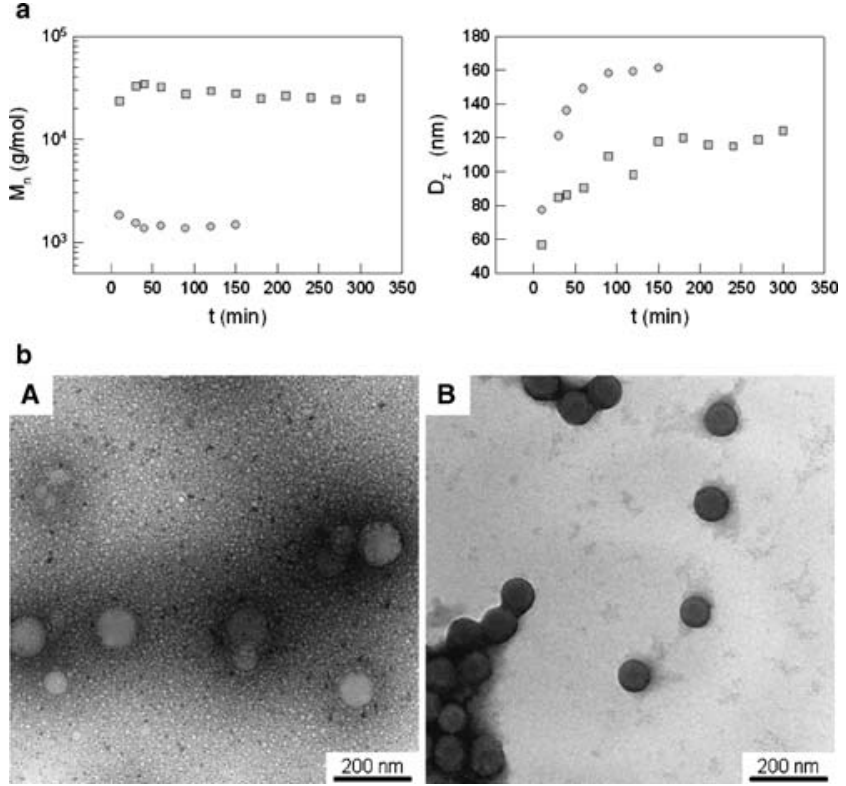

Fig. 16 a Development of the number average molecular weight $\left(M_{\mathrm{n}}\right)$, and the average particle size $\left(D_{\mathrm{Z}}\right.$ from Zetasizer) during nonstirred surfactant-free emulsion polymerizations of styrene with 120 min monomer equilibration time; experimental conditions: allglass reactor, $70{ }^{\circ} \mathrm{C}, 20 \mathrm{ml}$ of styrene, $562.5 \mathrm{~g}$ of water, $1.25 \mathrm{~g}$ of KPS (spheres) and $0.094 \mathrm{~g}$ of KPS (squares) b TEM images of particles after polymerization time of $30 \mathrm{~min}$ for nonstirred surfactant-free emulsion polymerizations of styrene with $120 \mathrm{~min}$ monomer equilibration time; experimental conditions: all-glass reactor, $70^{\circ} \mathrm{C}, 20 \mathrm{ml}$ of styrene, $562.5 \mathrm{~g}$ of water, $1.25^{\circ} \mathrm{g}$ of KPS $(A)$ and $0.094^{\circ} \mathrm{g}$ of KPS (B)

the theoretical description and, on the other hand, offer novel possibilities for the modification of latex particles.

$$
\left(\frac{2 \cdot \sigma}{r}\right) \cdot \frac{v_{1}}{R \cdot T}=-\left[\ln \left(1-\phi_{2}\right)+\left(1-1 / j_{2}\right) \cdot \phi_{2}+\chi \cdot \phi_{2}^{2}\right]
$$

The light microscopy image of Fig. 17 reveals that the particles which are in closer contact to the oil phase swell at a given time larger than those in farther distance from the

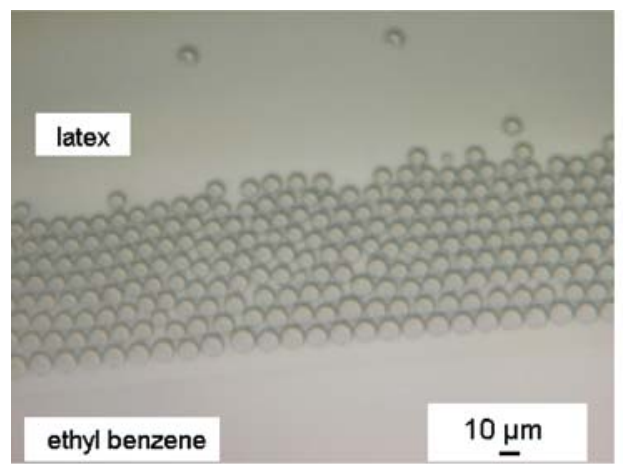

Fig. 17 Light microscopy image of polystyrene particles in contact with ethyl benzene ( $5 \mathrm{~h}$ after contacting) and change of the volume fraction of ethyl benzene per particle in dependence on the distance from the interface between the latex and ethyl benzene at different interface. This behavior is expressed quantitatively with the graph on the right hand side of Fig. 17. Same symbols correspond to a particular time after the contact between the latex and the swelling agent has been established. The volume fraction of swelling agent in the particles is plotted in dependence on the distance of the particle from the interface to the swelling agent. Each column of data points corresponds to a row of particles starting with row 1 at the distance zero. The last data point above $80 \mu \mathrm{m}$ in distance stems from row 9. The volume fraction of ethyl benzene in the particles increases from row 6 almost linearly the closer the particles are located to the interface (region marked by line ' $a$ ' in Fig. 17). Farther away from the interface than row 6 and about $6 \mathrm{~h}$ after the exposure, the volume fraction is almost independent of the distance $\left(\phi_{E B} \sim 0.75\right.$, region marked by line ' $b$ ' in Fig. 17).

For these particular polystyrene particles sitting in the first row, it takes about $3-4 \mathrm{~h}$ to reach the swelling equilibrium at room temperature. The data presented in Figs. 17 and 18 are, to the best of our knowledge, the first determination of the swelling kinetics by evaluating the size increase of individual particles. The equilibrium volume fraction of ethyl benzene is about 0.9 corresponding to a swollen particle size of about $12 \mu \mathrm{m}$ which is in quite good agreement with the prediction of the MKA equation if the interfacial tension is about $50 \mathrm{mN} / \mathrm{m}$ (cf. Fig. 19). However, this interfacial tension is surely too high as it is only $32 \mathrm{mN} / \mathrm{m}$ between neat polystyrene and water [37]. This result points to the fact that the MKA equation overestimates swelling which is compensated by using an unrealistic high interfacial tension as discussed in $[9,10]$.

Two interesting experimental observations made during the light microscopy investigations are noteworthy. First, latex particles sitting in the first row are captured from time to time by the organic phase. Thus, at equilibrium, swollen latex particles are in contact with a polymer solution and not with a neat solvent phase. During swelling, the

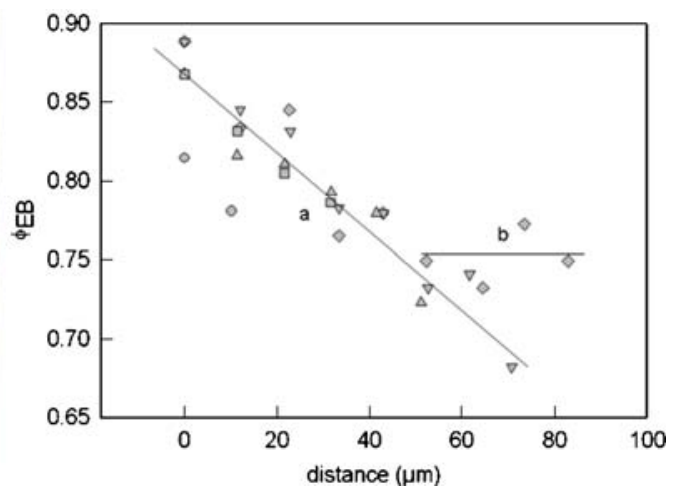

times; the diameter of the unswollen particles is $5.8 \pm 0.5 \mu \mathrm{m}$; exposure time: $145 \mathrm{~min}$ (spheres), $185 \mathrm{~min}$ (squares), $244 \mathrm{~min}$ (upright triangles), $364 \mathrm{~min}$ (inverted triangles), $425 \mathrm{~min}$ (diamonds); the lines are just for guiding the eyes 


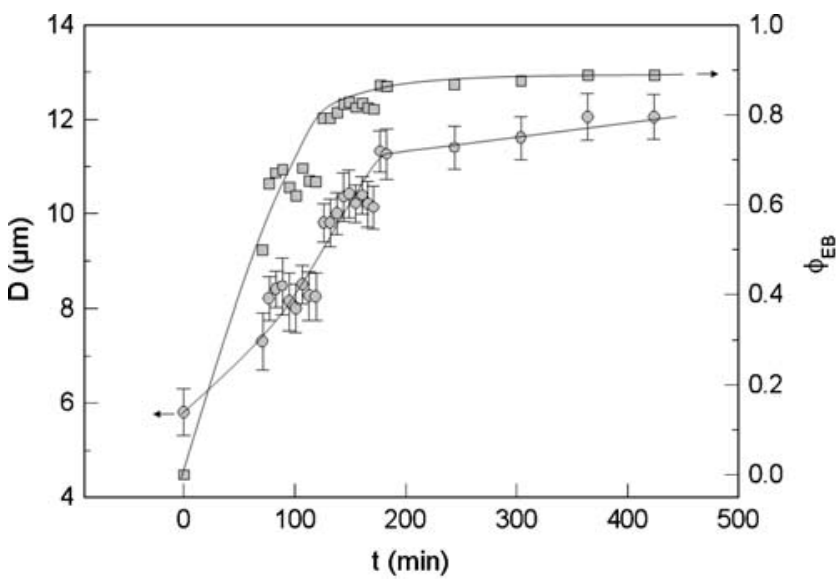

Fig. 18 Swelling kinetics of polystyrene particles with ethyl benzene at room temperature expressed as increase in the diameter $(D$, spheres) and volume fraction of ethyl benzene ( $\phi_{\mathrm{EB}}$, squares); $\phi_{\mathrm{EB}}$ values are calculated with the average values of $D$ for a given time

chemical potential of the solvent in the particles increases and in the liquid phase decreases until it is equilibrated.

Second, swelling of latex particles is cooperative in nature. If a solution is in contact instead of a pure solvent also solute molecules are transferred into the latex particles. This happens even if the solute is a chemically different polymer as demonstrated by the images of Fig. 20 proving the transfer of pyrene-labeled poly(methyl methacrylate) into polystyrene particles.

These results have important consequences for carrying out emulsion polymerization and for the modification of polymer latexes. There is a possibility to produce composite latex particles simply by swelling with appropriate solutions. In monomer-flooded polymerizations, the monomer phase will always contain a certain amount of polymer either as a result of the capture of latex particle by

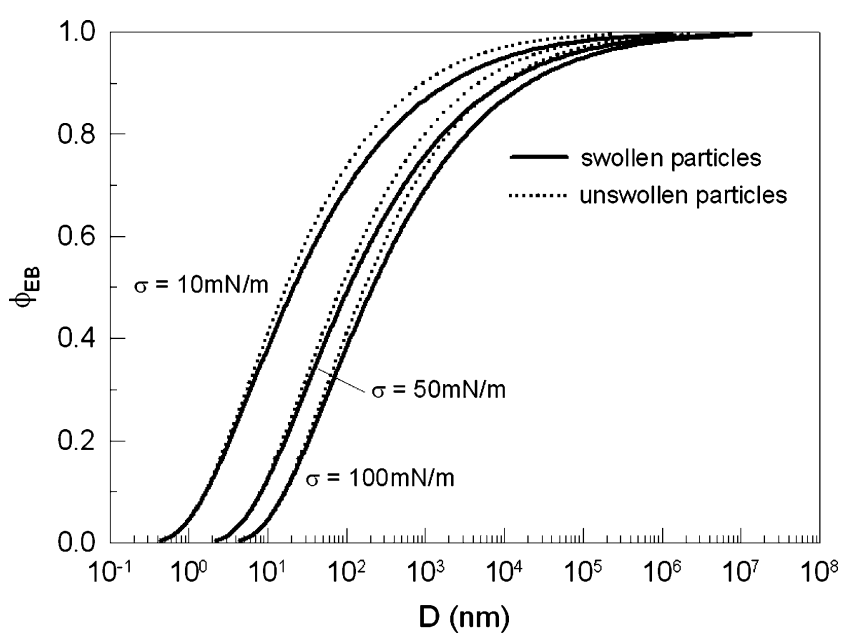

Fig. 19 Volume fraction of ethyl benzene in polystyrene particles in dependence of the particle size; the calculations have been carried out using Eq. 1 with a Flory-Huggins interaction parameter of 0.5 and a temperature of $25^{\circ} \mathrm{C}$

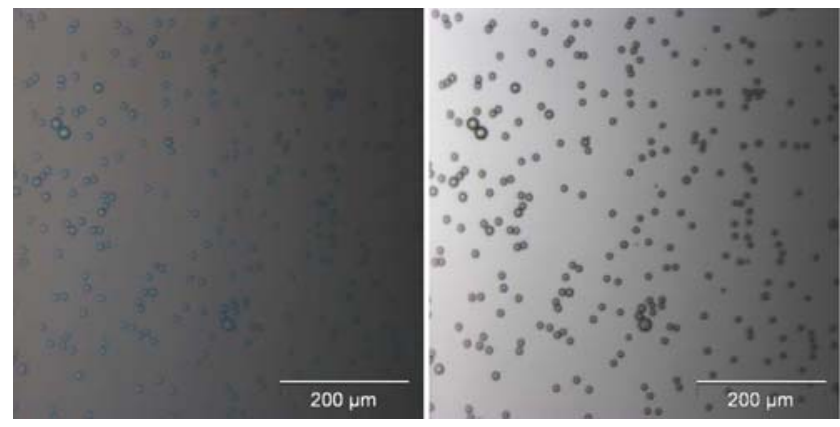

Fig. 20 Light microscopy images of swollen polystyrene latex particles; right, bright field image; left, fluorescence light image; the polystyrene particles are in contact with a solution of poly((pyrenyl methacrylate)co-(methyl methacrylate)) in ethyl benzene; images were taken about 4 weeks after contacting the latex with the copolymer solution; the pyrene-labeled copolymer was prepared as described in [38]

monomer droplets or as a result of direct polymerization inside the monomer droplets because radicals can be absorbed as well.

During emulsion polymerization of hydrophobic monomers, the main reaction loci for monomer conversion are the latex particles. Besides swelling of the particles with monomer, this requires also the capture of radicals from the continuous phase which then continue to grow inside the particles. For the uptake of radicals by latex particles, four mechanisms are discussed differing regarding the dependence of the capture rate coefficient $\left(k_{\mathrm{c}}\right)$ on the particle size $\left(k_{c} \propto D^{\alpha}\right)$. The collision model predicts $\alpha=2[39,40]$, the diffusion model $\alpha=1$ [41, 42], the colloidal model also $\alpha=1$ [43], and the propagational model $\alpha=0$ [11]. Interestingly, experimental results have been published proving the validity of all models. Obviously, each of these models is only valid for a certain range of experimental conditions. This is an insufficient situation showing that the general behavior regarding the absorption of matter by latex particles has not yet been understood.

Recently, it has been shown that Brownian dynamics (BD) simulations [44] are quite useful to achieve a deeper understanding of the absorption of matter by latex particles. These numerical experiments allow effective simulation of a variety of experimental conditions regarding the size and the concentration of the particles. Note that models relying on the Smoluchowski equation are insufficient, as it is valid for a single particle at infinite dilution [45]. However, in real emulsion polymerizations, the volume fraction of the polymer particles $\left(\phi_{\mathrm{p}}\right)$ can be well above $50 \%$.

With the Brownian dynamics simulations, the capture time of a species by particles was numerically determined. The capture time $(\tau)$ is the time between the introduction of the particular species in the system and its irreversible capture by the particles. The capture rate constant $k_{\mathrm{c}}$ relates with $\tau$ according to Eq. 2 where $N$ is the particle number in the dispersion volume (that is the volume of the continuous 
phase plus the overall particle volume) and $N_{\mathrm{A}}$ is Avogadro's number.

$k_{c}=\frac{N_{\mathrm{A}}}{N\langle\tau\rangle}$

The numerical simulations revealed that $k_{\mathrm{c}}$ depends on the particle size with a power which itself changes effectively with the polymer volume fraction. For very low polymer-volume fraction, $k_{c} \propto D(\alpha=1)$ as predicted by the Smoluchowski Eq. 3 where $\widetilde{D}_{r}$ is the diffusion coefficient of the absorbed species with a size much smaller than the particles.

$k_{c}=2 \pi \widetilde{D}_{r} D N_{\mathrm{A}}$

However, with increasing polymer volume fraction, $k_{\mathrm{c}}$ increases above the value given by Eq. 3. Thus, a dimensionless number, $\mathrm{Sm}$ (Smoluchowski number), can be defined by Eq. 4 relating the actual $k_{\mathrm{c}}$ value to $2 \pi \widetilde{D}_{r} D N_{A}$.

$S m=\frac{k_{\mathrm{c}}}{2 \pi \widetilde{D}_{r} D N_{\mathrm{A}}}$

The numerical results of the calculations (cf. Fig. 21) for a wide range of $D$ and $N$ values can be fitted in a satisfying manner by Eq. 5 where $v=17.95$ for the particular (mainly geometrical) conditions of the simulation.

$S m=1+v \phi_{\mathrm{p}}$

The polymer volume fraction can be modified by the two independent variables particle size and particle number. For extremely low-volume fractions $\left(\phi_{\mathrm{p}}<10^{-4}\right)$, the radical capture is determined by the Smoluchowski equation. These results of the numerical simulations, as given by

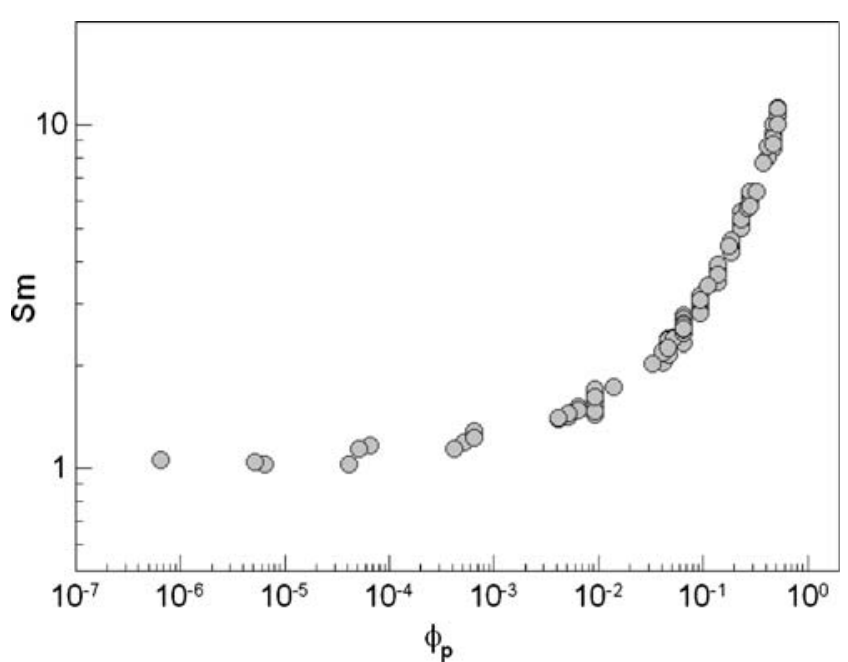

Fig. 21 Dependence of the capture rate of small molecules by particles in a polymer dispersion expressed by the Smoluchowski number $(\mathrm{Sm})$ on the polymer volume fraction $\left(\phi_{\mathrm{p}}=\pi / 6 \cdot D^{3} \cdot N\right)$
Eq. 5 and Fig. 21, are reasonable and fit with the various experimental data for radical capture by latex particles.

It is necessary to point out again that this behavior is not restricted to radicals, but it should be valid for all kinds of matter with a size smaller than the absorbing particles.

Moreover, the absorption or capture rate depends on the size of the absorbed species as expressed by their diffusion coefficients $\left(\widetilde{D}_{r}\right)$. The smaller the species, the higher is the capture rate by the larger particles as verified by numerical simulations. Moreover, the simulations show that the capture rate depends on the relative position of the absorbed species to the particle. The closer to the particle surface the species is generated or born or introduced, the higher the capture rate. This is clearly in accordance with experimental data as shown exemplarily in Fig. 17.

The results of the numerical simulations based on the Brownian dynamics are useful to evaluate problems in relation with the general mechanism of emulsion polymerization. A first example is related to the discussion regarding the micellar nucleation mechanism and concerns the estimation of the number of micelles at which the capture rate $\left(r_{\mathrm{cm}}\right.$, Eq. 6) of a radical from the water phase $\left[R_{\mathrm{aq}}\right]$ equals the propagation rate in water $\left(r_{\mathrm{paq}}, \mathrm{Eq} .7\right)$. From Eqs. 6 and Eq. 7 follows the quadratic Eq. 8 with the solution 9 for the number of micelles $\left(N_{\mathrm{m}}\right)$.

$$
\begin{aligned}
r_{c m}= & k_{c} \frac{N_{m}}{N_{A}}\left[R_{a q}\right]=2 \pi \widetilde{D}_{r} N_{A}\left(\frac{v \pi N_{m} D_{m}^{4}}{6}+D_{m}\right) \\
& \frac{N_{m}}{N_{A}}\left[R_{a q}\right]=2 \pi \widetilde{D}_{r}\left(\frac{v \pi N_{m} D_{m}^{4}}{6}+D_{m}\right) N_{m}\left[R_{a q}\right] \\
r_{\mathrm{paq}}= & k_{\mathrm{p}}\left[M_{\mathrm{aq}}\right]\left[R_{\mathrm{aq}}\right]
\end{aligned}
$$

$N_{\mathrm{m}}^{2}+\frac{6}{v \pi D_{\mathrm{m}}^{3}} N_{\mathrm{m}}-\frac{3 k_{\mathrm{p}}\left[M_{\mathrm{aq}}\right]}{v \pi^{2} D_{\mathrm{m}}^{4} \widetilde{D}_{r}}=0$

$N_{\mathrm{m}}=\frac{1}{2}\left(\frac{6}{v \pi D_{\mathrm{m}}^{3}}+\sqrt{\left(\frac{6}{v \pi D_{\mathrm{m}}^{3}}\right)^{2}+\frac{12 k_{\mathrm{p}}\left[M_{\mathrm{aq}}\right]}{v \pi^{2} D_{\mathrm{m}}^{4} \widetilde{D}_{r}}}\right)$

Considering styrene emulsion polymerization $\left(50{ }^{\circ} \mathrm{C}\right.$ with the propagation rate constant $k_{\mathrm{p}}=237 \mathrm{1} \mathrm{mol}^{-1} \mathrm{~s}^{-1}$, the monomer concentration in water $\left[M_{\mathrm{aq}}\right]=4.3 \cdot 10^{-3} \mathrm{M}$, the diameter of a swollen micelle $D_{\mathrm{m}}=10 \mathrm{~nm}$, and $\widetilde{D}_{r}=2 \times 10^{-9} \mathrm{~m}^{2} \mathrm{~s}^{-1}$ ) the propagation rate in the aqueous phase equals the rate of capture of radicals by micelles at $N_{\mathrm{m}}=8.11 \times 10^{15} \mathrm{~m}^{-3}$ corresponding to a volume fraction of micelles as low as $4.25 \times 10^{-9}$. This means that already at surfactant concentrations just above the $\mathrm{CMC}$, micelles can kinetically compete with the styrene molecules for the 
radicals which is actually good for micellar nucleation. That micellar nucleation is experimentally not observed might have several reasons. Either the radical grows out of the micelle into the water phase as Harkins [23-26] already suspected, or the micelle is destroyed by the inside-growing radical (either by the heat of propagation or due to the incompatibility between the surfactant and the polymer chain), and the only millisecond lifetime of a low-molecularweight surfactant micelle [46] is effectively still further reduced, or there exists an effective quite high energy barrier counteracting the entry of the radicals. BD simulations [47] with varying energy barrier clearly evidenced that the capture efficiency decays exponentially with the height of the energy barrier. Contrarily, the radical capture coefficient remains almost constant until certain "apparent" threshold energy before it shows the expected exponential decay. This means that a radical hits the same particle several times before it goes away again unless radical capture occurs. The threshold energy is larger than ten times $k_{\mathrm{B}} T$. The $\mathrm{BD}$ simulations do not contradict the experimental results showing that nucleation is practically unchanged in the presence of micelles but can be prevented in the presence of seed particles with a volume fraction of about $2 \times 10^{-2}$. The effective volume fraction for preventing nucleation must be much higher than the value estimated above for $r_{\mathrm{cm}}=r_{\mathrm{paq}}$ as the capture rate must be so high that the accumulation of nucleable oligomers in the water phase can be prevented.

A second example deals with the question whether single molecules or nano-droplets contribute mainly to the swelling of latex particles. Applying Eq. 6 to the absorption of clusters of monomers $(C)$ by latex particles $\left(N_{\mathrm{P}}\right)$ with diameter $D$ results in Eq. 10 for the absorption rate $\left(r_{\mathrm{abc}}\right)$, where $[C]$ is the cluster concentration relative to the volume of water. For the diffusion coefficient of the clusters composed of $n_{\mathrm{sm}}$ single monomer molecules, $\widetilde{D}_{c}$, and the cluster concentration hold the relations $11 \mathrm{a}$ and $11 \mathrm{~b}$, respectively. $D_{\mathrm{sm}}$ is the size of a single monomer molecule and $\widetilde{D}_{s m}$ its diffusion coefficient.

$r_{\mathrm{abc}}=2 \pi \widetilde{D}_{c} D\left(v \phi_{\mathrm{p}}+1\right) N_{\mathrm{P}}[C]\left(1-\phi_{\mathrm{p}}\right)$

$\widetilde{D}_{c}=\frac{D_{\mathrm{sm}}}{D} \widetilde{D}_{\mathrm{sm}}=n_{\mathrm{sm}}^{-1 / 3} \widetilde{D}_{\mathrm{sm}}$

$[C]=\frac{\left[M_{\mathrm{aq}}\right]}{n_{\mathrm{sm}}}$

Equation 12, relating the absorption rate of clusters to that of single monomer molecules $\left(r_{\mathrm{absm}}\right)$, shows that the absorption rate for single molecules is higher than for clusters. Moreover, the absolute rate of monomer uptake (that is, the swelling rate of a particle) is also higher for the absorption of single molecules, as only $n_{\mathrm{sm}}$ molecules are transferred per collision between a cluster and a particle.

$r_{\mathrm{abc}}=n_{\mathrm{sm}}^{-4 / 3} r_{\mathrm{absm}}$

\section{Conclusions}

Emulsion polymerization is a quite complex process that comprises several steps proceeding on very different time scales. Particle growth takes place on time scales that are in the order of the duration of the polymerization reaction, and hence, it is quite easy to study. However, some important reactions such as particle nucleation or radical entry have much smaller characteristic time constants making on-line investigation experimentally extremely challenging. Experimental results throwing light upon essential steps of emulsion polymerizations such as particle nucleation and the uptake of monomers and radicals by the particles require particularly designed experiments rather than the analysis of conversion-time curves of standard emulsion polymerizations. Moreover, thinking out of the box of established models opens new possibilities to gain knowledge.

The analysis of particle nucleation requires slowing down the reaction rate and a combination of various methods. Conductivity measurement is an extremely useful tool to identify the mechanism of particle nucleation. The experimental data obtained so far give no hint that micelles of low-molecular-weight surfactants are a major locus of particle formation. The data show that particle nucleation takes place outside the micelles and can be understood as aggregative nucleation within the frame of the classical nucleation theory [6]. Just after nucleation, the particles have a size of a few nanometers $(D<5 \mathrm{~nm})$ and are composed of quite a few water-borne oligomers. Surfactants influence the particle nucleation kinetics in several ways. If the aqueous phase is not yet equilibrated with monomer, the transfer of monomer to the aqueous phase is facilitated, and subsequently, the duration of the prenucleation period is shortened. The presence of surfactant molecules in the aqueous phase causes the formation of a higher concentration of smaller monomer drops due to spontaneous or forced emulsification. Moreover, surfactant molecules lower the interfacial tension of the particle nuclei and increase thereby the rate of nucleation.

However, the presence of seed particles can effectively prevent the formation of new particles as, above a critical volume fraction, they act as absorbers for any kind of smaller-sized matter present in the dispersion.

Brownian dynamics simulations suggest that any kind of species (radicals, monomers, and oligomers) can enter latex particles in dependence on their size for a given polymer volume fraction. In this sense and in contradiction to the 
propagational entry model [11], primary radicals can enter latex particles as it was proven also experimentally [12]. Besides radical entry, also swelling of latex particles with solvents or solutions can be treated as the simulations show that particles can take up any object present in the dispersion where the capture rate is primarily controlled by their size (diffusion coefficient). Swelling of latex particles with monomer must not necessarily take place via the uptake of single molecules as also monomer droplets are present in the aqueous phase. This spontaneous emulsification that takes place if two immiscible liquids are present [34] has enormous consequences for the mechanism of emulsion polymerization, not only for swelling but also for particle formation. Furthermore, it offers possibilities to modify latex particles by post-polymerization treatment.

In industry, it is the state of the art to carry out semibatchseeded emulsion polymerizations under monomer-starved conditions [1]. Such production protocols are advantageous as they avoid all uncertainties connected with particle nucleation and the presence of a free monomer phase. The results presented here for batch $a b$ initio polymerizations in the presence of free monomer are at least relevant for the seed production where particle nucleation takes place. Under industrially relevant conditions, that is, in the presence of surfactants and with stirring where emulsification is forced, the details of the nucleation process are not visible as the state of the monomer in the continuous phase is fixed and cannot be varied in such width and detail as in the present study.

Despite the fact that emulsion polymerization is one of the oldest industrial technologies for the production of polymers, new experimental approaches can still lead to the discovery of new experimental facts and to better understanding.

Acknowledgements The authors gratefully acknowledge financial support from the Max Planck Society and technical assistance from Mrs. Ursula Lubahn, Mrs. Sylvia Pirok, Mrs. Rona Pitschke, Mrs. Heike Runge, Mrs. Antje Völkel, and Mrs. Eugenia Maximova (MPI of Plant Physiology). O. L. is thankful for a fellowship provided by the German Academic Exchange Service (DAAD) within the Michail Lomonosov Program.

\section{References}

1. Urban D, Distler D (2002) Introduction. In: Urban D, Takamura K (eds) Polymer dispersions and their industrial applications. WileyVCH Verlag GmbH, Weinheim, p 1

2. El-Aasser MS, Sudol ED (1997) Features of emulsion polymerization. In: Lovell PA, El-Aasser MS (eds) Emulsion polymerization and emulsion polymers. Wiley, New York, p 37

3. Fitch RM (1997) Polymer colloids. A comprehensive introduction. Academic, San Diego
4. Gilbert RG (1995) Emulsion polymerization. Academic, London

5. van Herk A (2005) Chemistry and technology of emulsion polymerization. Blackwell, Oxford, UK

6. Tauer K, Kühn I (1995) Macromolecules 28:2236

7. Tauer K, Kühn I (1997) Particle nucleation at the beginning of emulsion polymerization. In: Asua JM (ed) NATO ASI Series, Series E: Applied Sciences, 335. p 49

8. Morton M, Kaizerman S, Altier MW (1954) J Coll Sci 9:300

9. Antonietti M, Kaspar H, Tauer K (1996) Langmuir 12:6211

10. Tauer K, Kaspar H, Antonietti M (2000) Coll Polym Sci 278:814

11. Maxwell IA, Morrison BR, Napper DH, Gilbert RG (1991) Macromolecules 24:1629

12. Tauer K, Nozari S, Ali AMI (2005) Macromolecules 38:8611

13. Tauer K, Antonietti M, Rosengarten L, Müller H (1998) Macromol Chem Phys 199:897

14. Walz R, Bomer B, Heitz W (1977) Makromol Chem - Macromol Chem Phys 178:2527

15. Kozempel S (2005) PhD thesis, Emulgatorfreie Emulsionspolymerisation-zonomerlösungszustand und Teilchenbildung, University of Potsdam

16. Kühn I, Tauer K (1995) Macromolecules 28:8122

17. Tauer K, Deckwer R, Kuhn I, Schellenberg C (1999) Coll Polym Sci 277:607

18. Tauer K, Kühn I, Kaspar H (1996) Progr. Coll Polym Sci 101:30

19. Laaksonen A, Talanquer V, Oxtoby DW (1995) Ann Rev Phys Chem 46:489

20. Tauer K, Mukhamedjanova M, Holtze C, Nazaran P, Lee J (2007) Macromol Symp 248:227

21. Tauer K (1995) Polym Adv Technol 6:435

22. Holtze C, Antonietti M, Tauer K (2006) Macromolecules 39:5720

23. Harkins WD (1947) J Amer Chem Soc 69:1428

24. Harkins WD (1945) J Chem Phys 13:381

25. Harkins WD (1946) J Chem Phys 14:47

26. Harkins WD (1950) J Polym Sci 5:217

27. Smith WV, Ewart RH (1948) J Chem Phys 16:592

28. Roe CP (1968) Ind Eng Chem 60:20

29. Bartholome E, Gerrens H, Herbeck R, Weitz HM (1956) Z Elekrtochem 60:334

30. Hansen FK, Ugelstad J (1979) J Polym Chem Part A Polym Chem 17:3047

31. Brooks BW, Makanjuola BO (1981) Makromol Chem-Rapid Commun 2:69

32. Okubo M, Mori T (1990) Makromol Chem-Macromol Symp 31:143

33. Kozempel S, Tauer K, Rother G (2005) Polymer 46:1169

34. Tauer K, Kozempel S, Rother G (2007) J Coll Interf Sci 312:432

35. McAskill NA, Sangster DF (1984) Aust J Chem 37:2137

36. Neta P, Madhavan V, Zemel H, Fessenden RW (1977) J Amer Chem Soc 99:163

37. Vijayendran BR (1979) J Appl Polym Sci 23:733

38. Saito N, Kagari Y, Okubo M (2006) Langmuir 22:9397

39. Fitch RM, Tsai CH (1971) Polym Coll Proc Symp 73

40. Gardon JL (1968) J Polym Sci Part A-1 Polym Chem 6:623

41. Hansen FK, Ugelstad J (1978) J Polym Chem Part A Polym Chem $16: 1953$

42. Ugelstad J, Hansen FK (1976) Rub Chem Technol 49:536

43. Penboss IA, Gilbert RG, Napper DH (1986) J Chem Soc-Farad Trans I 82:2247

44. Hernandez HF, Tauer K (2007) Ind Eng Chem Res 46:4480

45. von Smoluchowski M (1906) Ann Phys 21:756

46. Fuhrhop J-H, Köning J (1994) Membranes and Molecular Assemblies. The Royal Society of Chemistry, Cambridge

47. Hernandez HF, Tauer K (2007) Macromol Symp in press 